\title{
Article
}

\section{Mineralogical classification and crystal water characterisation of beryl from the W-Sn-Be occurrence of Xuebaoding, Sichuan province, western China}

\author{
Ping Wang1,§, Thomas P. Gray², Zhe Li³, Evan J.D. Anderson², Julien Allaz ${ }^{4}$, Joseph R. Smyth ${ }^{5}$, Alan E. Koenig6, $†$, \\ Lijian $\mathrm{Qi}^{7}$, Yan Zhou ${ }^{7}$ and Markus B. Raschke ${ }^{2 \star}$ it \\ ${ }^{1}$ College of Physics, Sichuan University, Chengdu, Sichuan, 610064, China; ${ }^{2}$ Department of Physics, Department of Chemistry, and JILA, University of Colorado, \\ Boulder, CO 80303, USA; ${ }^{3}$ Institute of Fundamental and Frontier Sciences, University of Electronic Science and Technology of China, Chengdu, Sichuan, 610054, \\ China; ${ }^{4}$ ETH Zürich, Department of Earth Sciences, Institute of Geochemistry and Petrology, Clausiusstrasse 25, 8092 Zurich, Switzerland; ${ }^{5}$ Department of Geological \\ Sciences, University of Colorado, Boulder, CO 80303, USA; ${ }^{6}$ United States Geological Survey, Geology, Geophysics, and Geochemistry Science Center, Lakewood, \\ Colorado, USA; and ${ }^{7}$ Laboratory of Gem and Technological Materials, Tongji University, Shanghai 200070, China
}

\begin{abstract}
Beryl from Xuebaoding, Sichuan Province, western China is known for its unusual tabular habit and W-Sn-Be paragenesis in a greisentype deposit. The crystals are typically colourless transparent to pale blue, often with screw dislocations of hexagonal symmetry on the (0001) crystal faces. Combining electron microprobe analyses and laser ablation inductively coupled plasma mass spectrometry with single-crystal X-ray diffraction (XRD), correlated with Raman and micro-infrared (IR) spectroscopy and imaging, the crystal chemical characteristics are determined. The contents of $\mathrm{Na}^{+}\left(0.24-0.38\right.$ atoms per formula unit (apfu)) and $\mathrm{Li}^{+}$up to 0.38 apfu are at the high end compared to beryl from other localities worldwide. $\mathrm{Li}^{+}$substitution for $\mathrm{Be}^{2+}$ on the tetrahedral (T2) site is predominantly charge balanced by $\mathrm{Na}^{+}$on the smaller channel (C2) site, with $\mathrm{Na}^{+}$ranging from $91.5 \%$ to $99.7 \%$ (apfu) of the sum of all other alkali elements $\mathrm{Cs}^{+}$and minor $\mathrm{Rb}^{+}$and $\mathrm{K}^{+}$primarily charge balance the minor $M^{2+}$ substitution for $\mathrm{Al}^{3+}$ at the A site; all iron at the A site is suggested to be trivalent. The $a$ axis ranges from 9.2161(2) to 9.2171(4) $\AA$, with unit-cell volume from $678.03(3)$ to $678.48(7) \AA^{3}$. The $c / a$ ratio of 1.0002-1.0005 is characteristic for T2-type beryl with unit-cell parameters controlled primarily by Be ${ }^{2+}$ substitution. Transmission micro-IR vibrational spectroscopy and imaging identifies coordination of one or two water molecules to $\mathrm{Na}^{+}$(type IIs and type IId, respectively) as well as alkali free water (type I). Based on IR absorption cross section and XRD a C1 site water content of $0.4-$ 0.5 apfu is derived, i.e. close to $50 \%$ site occupancy. Secondary crystal phases with a decrease in $\mathrm{Fe}$ and $\mathrm{Mg}$, yet increase in $\mathrm{Na}$, suggest early crystallisation of aquamarine, with goshenite being late. With similar crystal chemistry to beryl of columnar habit from other localities worldwide, the tabular habit of Xuebaoding beryl seems to be unrelated to chemical composition and alkali content.
\end{abstract}

Keywords: beryl, Xuebaoding, crystal chemistry, tabular habit, crystal water, infrared spectroscopy

(Received 3 December 2020; accepted 31 January 2021; Accepted Manuscript published online: 3 February 2021; Associate Editor: Ferdinando Bosi)

\section{Introduction}

\section{Background}

Beryl as the most common beryllium mineral is of important geochemical significance in different geological contexts. Ideally $\mathrm{Be}_{3} \mathrm{Al}_{2} \mathrm{Si}_{6} \mathrm{O}_{18}$, beryl is a cyclosilicate mineral of hexagonal crystal structure. Six-membered rings of Si tetrahedra are linked by tetrahedrally coordinated $\mathrm{Be}^{2+}$ (T2 site) and octahedrally coordinated

${ }^{\S}$ Present address: Institute of Regulatory Science for Medical Devices, Sichuan University, Chengdu, Sichuan, 610064, China

${ }^{\dagger}$ Present address: Applied Spectra, Inc., West Sacramento, CA 95605, USA

${ }^{\star}$ Author for correspondence: Markus B. Raschke, Email: markus.raschke@colorado.edu Cite this article: Wang P., Gray T.P., Li Z., Anderson E.J.D., Allaz J., Smyth J.R., Koenig A.E., Qi L., Zhou Y. and Raschke M.B. (2021) Mineralogical classification and crystal water characterisation of beryl from the W-Sn-Be occurrence of Xuebaoding, Sichuan province, western China. Mineralogical Magazine 85, 172-188. https://doi.org/10.1180/ mgm.2021.13
$\mathrm{Al}^{3+}$ (A site) in planes parallel to (0001) (Aurisicchio et al., 1988, 1994; Černý, 2002; Groat et al., 2008). The rings form channels parallel to the crystallographic $c$ axis, which in natural beryl typically contain variable amounts of primarily alkali cations and neutral molecules of water, $\mathrm{CO}_{2}$ and $\mathrm{CH}_{4}$ (Ginzburg, 1955; Wood and Nassau, 1968; Hawthorne and Černý, 1977; Aines and Rossman, 1984; Artioli et al., 1993; Charoy et al., 1996; Pankrath and Langer, 2002; Gatta et al., 2006; Groat et al., 2008; Fridrichová et al., 2016). The accommodation of monovalent alkali cations on the two channel vacancy sites charge balances the substitution of divalent or trivalent cations (e.g. $\mathrm{Mg}^{2+}$, $\mathrm{Fe}^{2+/ 3+}$ or $\mathrm{Mn}^{2+}$ ) for $\mathrm{Al}^{3+}$ at the $\mathrm{A}$ site, or the substitution of primarily $\mathrm{Li}^{+}$for $\mathrm{Be}^{2+}$ at the T2 site (Folinsbee, 1941; Wood and Nassau, 1968; Bakakin et al., 1969; Hawthorne and Černý, 1977; Aurisicchio et al., 1988). The smaller alkali $\mathrm{Na}^{+}$occupies the narrower channel site $(\mathrm{C} 2 / 2 \mathrm{~b})$, while the larger $\mathrm{K}^{+}, \mathrm{Cs}^{+}$or $\mathrm{Rb}^{+}$as well as $\mathrm{H}_{2} \mathrm{O}$ and $\mathrm{CO}_{2}$ prefer the wider channel site $(\mathrm{Cl} /$

(C) The Author(s), 2021. Published by Cambridge University Press on behalf of The Mineralogical Society of Great Britain and Ireland. This is an Open Access article, distributed under the terms of the Creative Commons Attribution licence (http://creativecommons.org/licenses/by/4.0/), which permits unrestricted re-use, distribution, and reproduction in any medium, provided the original work is properly cited. 
2a) (Aurisicchio et al., 1994; Łodziński et al., 2005; Fukuda and Shinoda, 2008). Pure beryl is colourless (var. goshenite), whereas different substitutions give rise to distinct colours of blue (var. aquamarine, $\mathrm{Fe}$ ), green (var. emerald, $\mathrm{Cr} / \mathrm{V}$ ), yellow (var. heliodor, Fe) or pink (var. morganite, Mn) (Lum et al., 2016; Tempesta et al., 2020).

Following early ultraviolet (UV), visible, and IR spectroscopy (Wood and Nassau, 1967, 1968), the lattice position, molecular orientation, bonding state and dynamic behaviour of water in natural and synthetic beryl, and at variable temperatures, have been characterised spectroscopically (Kim et al., 1995; Charoy et al., 1996; Kolesov and Geiger, 2000; Łodziński et al., 2005; Fukuda and Shinoda, 2008, 2011). Based on these studies, water on the $\mathrm{C} 1 / 2 \mathrm{a}$ sites has been defined as type I or type II with a molecular dipole moment orientated perpendicular or parallel with respect to the $c$ axis, respectively. In addition the preference for each type is controlled by the channel alkali content.

\section{Xuebaoding beryl}

One notable occurrence of beryl is the Xuebaoding greisen-type $\mathrm{W}-\mathrm{Sn}-\mathrm{Be}$ deposit in the Songpan-Ganzi (or Songpan-Garzê) orogenic belt in Sichuan Province, western China (Zhang et al., 2014). Explored since the 1950s, the occurrence is known for scheelite, cassiterite and beryl of exceptional size and gem quality, with quartz, fluorite and minor apatite formed in a postmagmatic hydrothermal process (Lin et al., 2000; Zhou et al., 2002; Liu et al., 2005). The abundant beryl is typically transparent and colourless to pale blue. In contrast to the common columnar prismatic habit of beryl parallel to the $c$ axis, Xuebaoding beryl is primarily of tabular habit parallel to the basal pinacoid.

Even though a range of studies have addressed the gemmology (Qi et al., 2001a, b, c, d) and mineralogy of beryl from Xuebaoding over more than two decades (Guo et al., 2000a, b; Lin et al., 2000; Ye et al., 2001; Zhou et al., 2002; Liu et al., 2007, 2012), its crystal chemistry has not yet been well established with several analytical results either inconclusive or in part contradictory, leading to a confusing picture even about elementary questions of composition and structure. Further, contrasting hypotheses were proposed, with crystal growth controlled by defects and dislocations (Qi et al., 2001b) or by high alkali content at the Be and channel sites (Liu et al., 2012) being responsible for the tabular habit.

\section{This work}

The goal of this work is a systematic chemical, including trace element, and structural classification of beryl from Xuebaoding including comparison with beryl from other localities, notably of comparable tabular habit. Further, water in its different structural states and its vibrational response are quantified by correlating single-crystal X-ray diffraction with Raman and IR micro-spectroscopy and imaging.

\section{Geographic and geological setting}

The sample localities are generally referred to as Xuebaoding (Sichuan Province, China) situated northwest of the Longmen Shan range, at the eastern margin of the Tibetan plateau, at elevations of 3900-4200 m. The locality is named after the mountain Xuebaoding ('Snow Treasure Crown', Tibetan name: Shar Dung $\mathrm{Ri}$, elevation $5,588 \mathrm{~m}$ ), the highest peak of the Minshan range.
However, Xuebaoding mountain itself is $5.3 \mathrm{~km}$ to the $\mathrm{NW}$ of the locality, and not visible from the locality, separated by several high ridges and the mountain Sigenxiangfeng $(5,360 \mathrm{~m})$. Instead, the peak visible to the immediate NW (Fig. 1a, top left), is Little Xuebaoding $(5,443 \mathrm{~m})$ and situated above the valley to the western terminus of the locality area. The confusion between the two peaks, including confusion about first ascents of these mountains persisted well into the 1980 s, and until today by the local population, as a reflection of the complex topography and extreme relative relief of up to $4000 \mathrm{~m}$ between the valley floors and adjacent peaks, with many of similar altitude.

Tectonically, the area is situated in the Songpan-Ganzi orogenic belt to the west of the Sichuan Province, near the contact with the Qinling orogenic belt (north) and the western Yangtze block (east and south-east) (Fig. 1b). The Songpan-Ganzi orogenic belt is the result of two stages of tectonic movements. Following the late Indochina tectonic epoch with long-term intracontinental convergence and associated series of magmatic and metamorphic events, the subsequent Himalayan movement starting at $\sim 80 \mathrm{Ma}$ resulted in a pronounced twist in the SongpanGanzi orogenic belt (Xu et al., 1992; Kirby and Ouimet, 2011). Along the Minshan (or Min Mountains) the active fault system of the N-S trending Huya fault, a steeply west-dipping reverse fault, contributes to the ongoing uplift of the Minshan. The Huya fault separates Precambrian basement and overlying late Proterozoic to Permian rock units to its east, from the Triassic Songpan-Ganzi flysch sequences to its west (Kirby and Ouimet, 2011). The numerous intruded granites in the eastern margin of the Tibetan plateau have been dated at 220 to $188 \mathrm{Ma}$ (Roger et al., 2004, 2010; Xiao et al., 2007).

\section{Geology of the Xuebaoding deposit}

The Xuebaoding mineralisation is associated with several Mesozoic leucogranite intrusions, of a few $100 \mathrm{~m}$ to $1 \mathrm{~km}$ in extent in outcrop (e.g. Pankou, Pukou and Wuzhutang), of similar spatial separation, and dated at 201-194 Ma (Fig. 1c) (Ye et al., 2001; Zhou et al., 2002; Cao et al., 2004; Jiang et al., 2007; Li et al., 2007). Whether these different outcrops are of a single intrusion, or represent separate intrusions, and their relationship is yet unknown. However, their similarities in rock type and associated mineralisation suggests at least a close magmatic relationship.

The granites intruded into the upper Triassic Zhuwo series of deep-marine sedimentation origin, accompanied by slate, schist and marble lenticules, as well as layers of marble of shallow metamorphism of late Indosinian orogeny to early Yanshan age (Zhou et al., 2002; Cao et al., 2004; Ottens, 2005; Li et al., 2007). The sequence of layers of sericite, quartz and carbonaceous schist, mudstone, marble and local skarn, are overturned, with shallow dip to the west, yet steeply dipping to the east of the granite contacts (Fig. 1c).

\section{Mineral assemblage}

The Xuebaoding locality is a globally significant occurrence of scheelite and cassiterite, in combination with beryl, all of unusually large size, gem colour, and crystal quality. It is a greisen-type deposit of quartz and muscovite. Albeit locally variable in relative distribution, the joint mineralisation of scheelite, cassiterite and beryl suggests that it is derived from a highly fractionated and evolved magma in the apical section of the granitic 

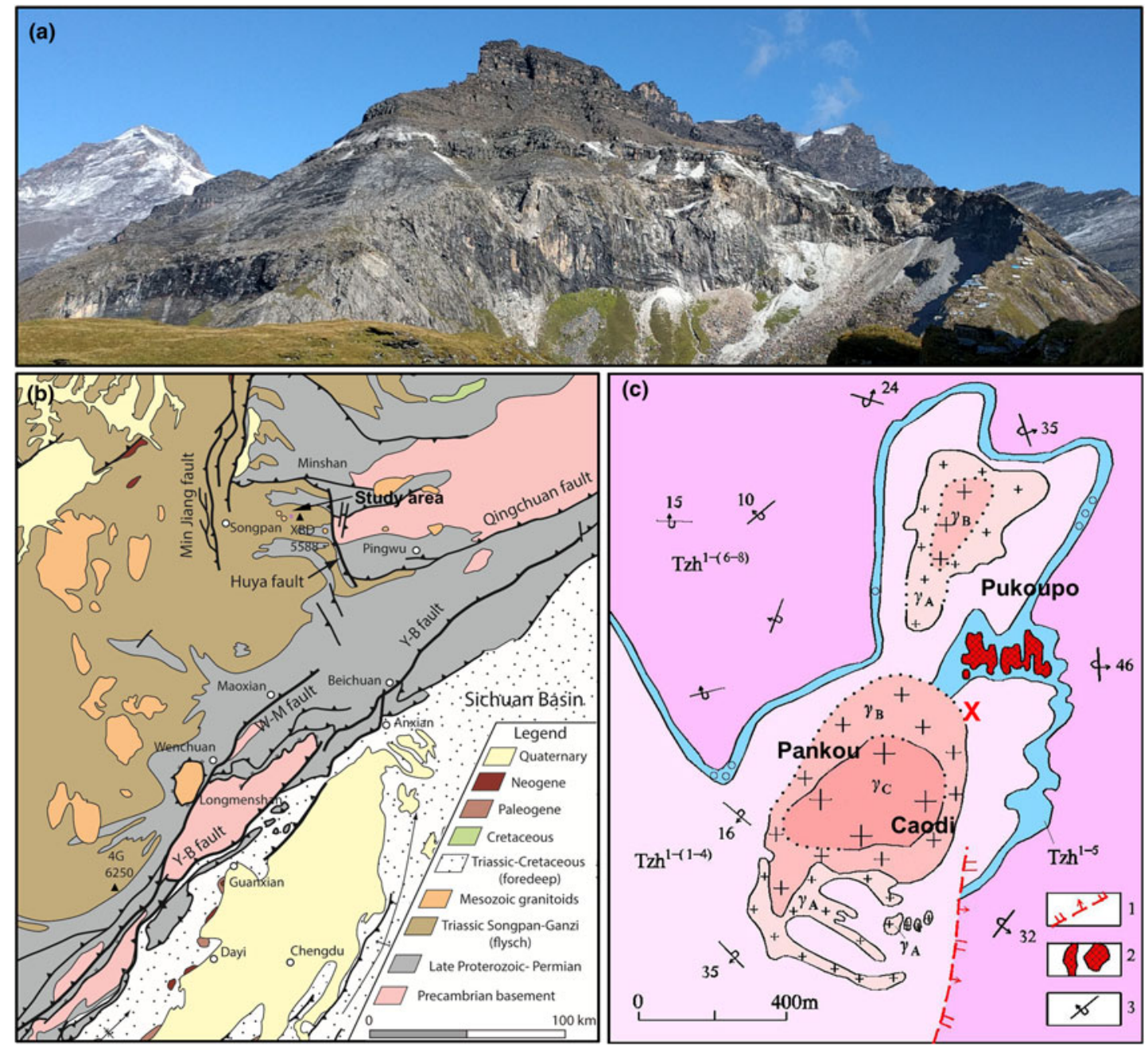

Fig. 1. (a) Xuebaoding locality, with Little Xuebaoding $(5,443 \mathrm{~m}$, left) in the background. Mineralised zones along a nearly horizontal marble band (white mine tailings) and in schist, along and below both sides of ridge to the right (mining camp at bottom right). (b) Generalised geological map of eastern margin of Tibetan plateau with Xuebaoding (XBD) mountain west of the Huya fault and to NE of the Longmen Shan range and uplift zone defined by Yingxiu-Beichuan (Y-B) and Wenchuan-Maoxian (W-M) faults; major peaks of Siguniangshan (4G) and Xuebaoding (XBD) indicated (modified with permission after Kirby and Ouimet, 2011). (c) Geological map of the main locality area (pink rectangle in (b)) associated with granite body outcrops Pankou and Caodi (defining the cirques in (a)) and Pukoupo. Legend: 1: normal fault, 2: highly mineralised quartz vein containing beryl, scheelite and cassiterite, 3: overturned dip and strike (modified

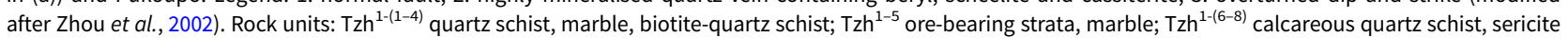
quartz schist; $\gamma_{\mathrm{A}-\mathrm{C}}$ granite margin through transition to core zone. The $\mathrm{W}-\mathrm{Sn}$-Be mineralisation is concentrated throughout schist and marble within $<100 \mathrm{~m}$ from

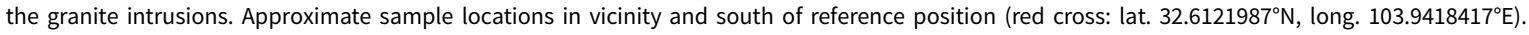

body (Cao et al., 2002, 2004; Li et al., 2007; Zhang et al., 2014; Zhu et al., 2020). Highly enriched in volatiles and metallic elements this gives rise to simple mineralisation of large, mostly common, W, Sn, Be, F and P minerals. The mineralisation of muscovite, with fluorite and apatite in addition to the $\mathrm{W}$ and $\mathrm{Sn}$ mineralisation is typical for an S-type granite derived system. The mineralisation is fracture-controlled and occurs in sheeted veins and stockwork, emanating from the greisenised granite into the country rock. However, associated post-magmatic alteration of the host rock by volatiles and solutions derived from the cooling granitic intrusion, as is otherwise typical for greisen, is not very pronounced (Aurisicchio et al., 1994).

Forming interconnected networks of quartz (with muscovite and fluorite), well-defined mineralised veins with a $\mathrm{N}-\mathrm{S}$ trend are found primarily in marble, with a more stockwork type in the surrounding schist. This reflects that the marble is more brittle forming fractures for fluids to circulate and deposit, with the schist more ductile. The different ore veins in granite, marble and schist as host rock with different generations and conditions with spatial and temporal variations in mineralisation exhibit large variations in mineral assemblage - with locally spatial ring fractures, replacement mineral bodies, distal vein emplacement, hydrothermal breccia boiling and hydrothermal alterations.

\section{Xuebaoding beryl}

The global occurrence of beryl, especially in large crystals, is typically associated with granitic pegmatites. Tungsten and tin mineralisations often occur simultaneously and are associated, but typically without beryl. Mineralisation of $\mathrm{W}$ and $\mathrm{Sn}$ together with $\mathrm{Be}$ is generally uncommon, which makes the combination of $\mathrm{W}, \mathrm{Sn}$ and Be mineralisation of the Xuebaoding occurrence, and not of a pegmatite-type but rather of a hydrothermal/greisentype, make Xuebaoding unusual.

Despite decades of research since the discovery of the localities in the 1950s (Guo et al., 2000a; Qi et al., 2001b; Cao et al., 2002; 

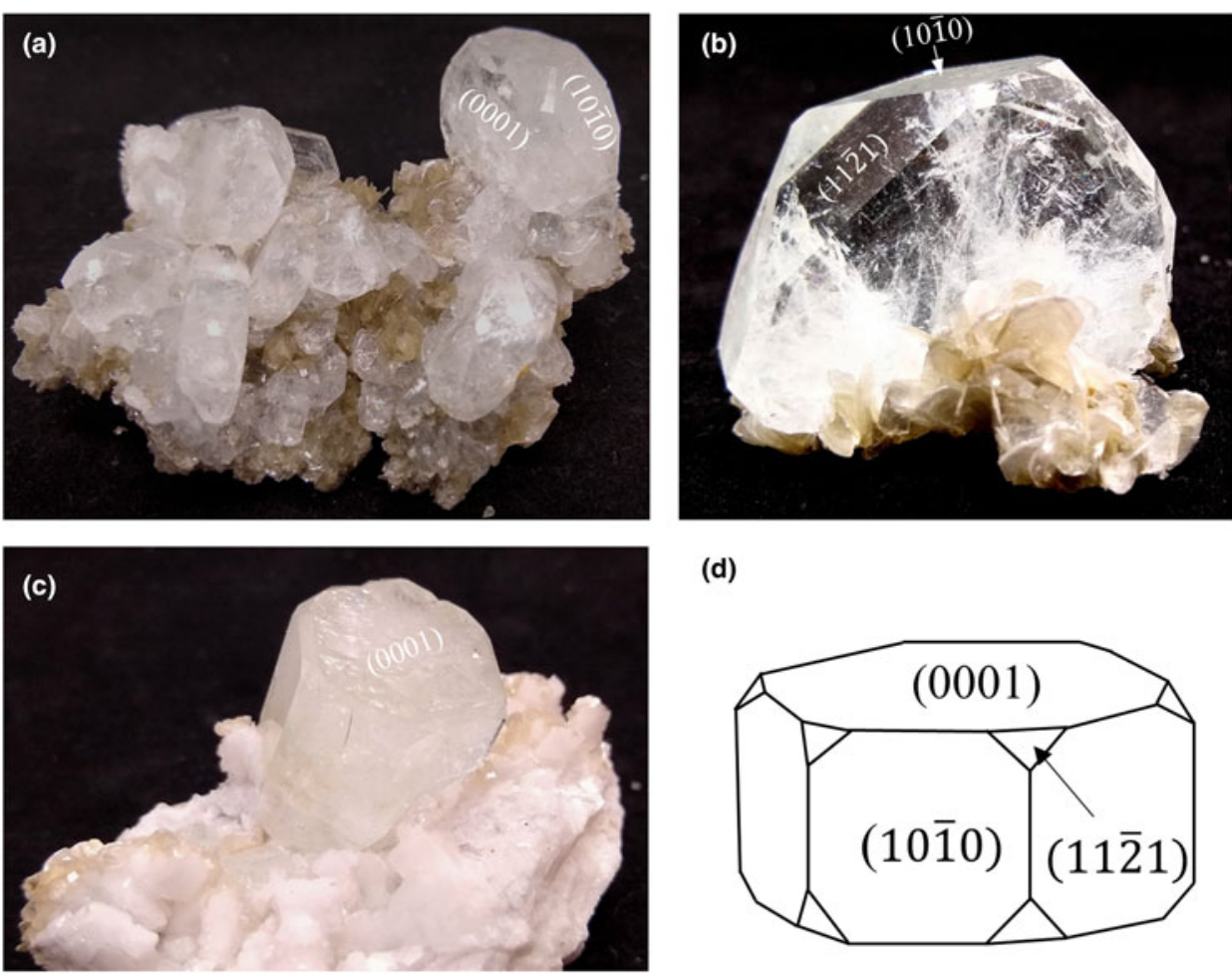

(d)

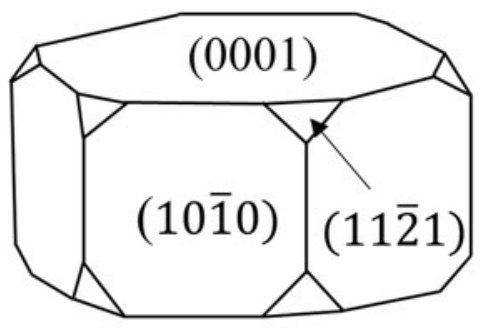

Fig. 2. Examples of representative Xuebaoding beryl habits: (a) cluster of tabular beryl on muscovite matrix (largest crystal $25 \mathrm{~mm}$ wide); (b) individual clear tabular crystal (40 mm wide); (c) rare columnar habit (on albite, $25 \mathrm{~mm}$ wide), light blue, with typical dislocation texture on (0001); (d) schematic of tabular habit.
Zhou et al., 2002; Liu et al., 2012; Zhang et al., 2012), only limited field studies have been undertaken and the ore-forming processes and source of the fluid are not yet clear. Further, despite several ages reported for granite and mineralisation, some are inconsistent, and it is unknown if they reflect the date of mineral formation.

Xuebaoding beryl is mostly colourless, transparent and rarely with a hint of blue. It typically exhibits a simple morphology, yet of characteristic tabular habit shortened in the $c$ direction, with the most common basal pinacoid (0001), prisms (1010) and $(11 \overline{2} 1)$ faces as shown in Fig. 2 . The habit is rarely columnar, and if so has a low aspect ratio (Fig. 2c).

Numerous studies covering a wide range of techniques have addressed selected aspects of the crystal chemistry of beryl from Xuebaoding (Guo et al., 2000a; Qi et al., 2001b; Cao et al., 2002; Zhou et al., 2002; Liu et al., 2012; Zhang et al., 2012). Specifically, several studies using bulk chemical analysis, electron microprobe analysis (EPMA), and laser ablation inductively coupled plasma mass spectrometry (LA-ICP-MS) identified enrichment in $\mathrm{Na}^{+}\left(\mathrm{Na}_{2} \mathrm{O}=0.035-1.66\right.$ wt.\% $)$ and $\mathrm{Li}^{+}\left(\mathrm{Li}_{2} \mathrm{O}=0.63-3.04\right.$ wt.\%) with variable amounts of $\mathrm{Cs}^{+}\left(\mathrm{Cs}_{2} \mathrm{O}=0.11-0.92\right.$ wt.\%), and minor $\mathrm{K}^{+}\left(\mathrm{K}_{2} \mathrm{O}=0.01-1.13\right.$ wt.\%), $\mathrm{Mg}^{2+}(\mathrm{MgO}=0.03-0.13$ wt.\%), $\mathrm{Ca}^{2+}(\mathrm{CaO}=0.01-0.88$ wt.\% $)$ and $\mathrm{Fe}^{3+}\left(\mathrm{FeO}_{\mathrm{T}}=0.06-0.54\right.$ wt.\%) (Liu et al., 2001b, 2005, 2012; Qi et al., 2001b; Zhou et al., 2002; literature data summarised in Supplementary Table S1). While some analyses are inconsistent, they confirm the trend that defines Xuebaoding beryl as a lithium-sodium or 'tetrahedron' beryl (Aurisicchio et al., 1988, 1994)

A comprehensive EMPA of beryl, whole rock analysis of granite, and fluid inclusion study suggested a post-magmatic pneumatolytic-hydrothermal solution as the source of the beryl mineralisation (Zhou et al., 2002). An X-ray fluorescence and LA-ICP-MS trace-element analysis, in combination with XRD, and surface textural features, identified $\mathrm{Li}^{+}$substitution at the tetrahedral $\mathrm{Be}^{2+}$ site together with divalent cation substitution for $\mathrm{Al}^{3+}$ with associated charge balancing by other alkali on the vacancy site (Liu et al., 2012). The high alkali content (0.255$0.327 \mathrm{apfu}$, not including $\mathrm{Li}^{+}$) was hypothesised to be responsible for the tabular crystal growth (Liu et al., 2012). In contrast, a detailed analysis of surface defects on different crystal phases in combination with a growth rate model as a function of supersaturation (Qi et al., 2001b) suggested interstitial deformation and dislocation sliding responsible for the different growth rate of basal $v s$. prismatic crystal faces giving rise to the tabular morphology (Zhang et al., 2012).

Several fluid-inclusion studies have been performed for quartz, beryl and scheelite identifying homogenisation temperatures covering a wide range of $214-288^{\circ} \mathrm{C}$ (Cao et al., 2002), $158-310^{\circ} \mathrm{C}$ (Zhou et al., 2002), $250-292^{\circ} \mathrm{C}$ (Chen et al., 2002), $265-315^{\circ} \mathrm{C}$ (Lin et al., 2000), $188-373^{\circ} \mathrm{C}$ (Zhang et al., 2012) and $266-389^{\circ} \mathrm{C}$ (Liu et al., 2005), suggesting a shallow hydrothermal quartz vein type system. These works imply a volatile-rich pneumatolytic-hydrothermal solution derived from post-magmatic fluid as a source of the mineralisation (Cao et al., 2002; Zhou et al., 2002). Related work suggests a temperature range of $250-292^{\circ} \mathrm{C}$, at high pressures $(\sim 86 \mathrm{MPa})$ with high $\mathrm{CO}_{2}$ density $\left(0.662 \mathrm{~g} / \mathrm{cm}^{3}\right)$, and low salinity (6.191 wt.\% $\mathrm{NaCl}$ ) during the formation of beryl (Chen et al., 2002). This is consistent with more recent work (Zhang et al., 2012) suggesting a temperature of beryl formation of $\sim 300^{\circ} \mathrm{C}$.

\section{Material and analytical methods}

For this study selected single crystals and rock-forming beryl were chosen from different veins and collected in situ. The rock-forming sample hosted in quartz schist $\mathrm{Tzh}^{1-(1-4)}$ has been extracted from an active mine on the east side of Pankou (thin section 1702B2, for details see Supplementary Fig. S1). Further, from clefts in veins hosted in marble $\mathrm{Tzh}^{1-5}$ small single crystals of $0.5-1.5 \mathrm{~cm}$ 

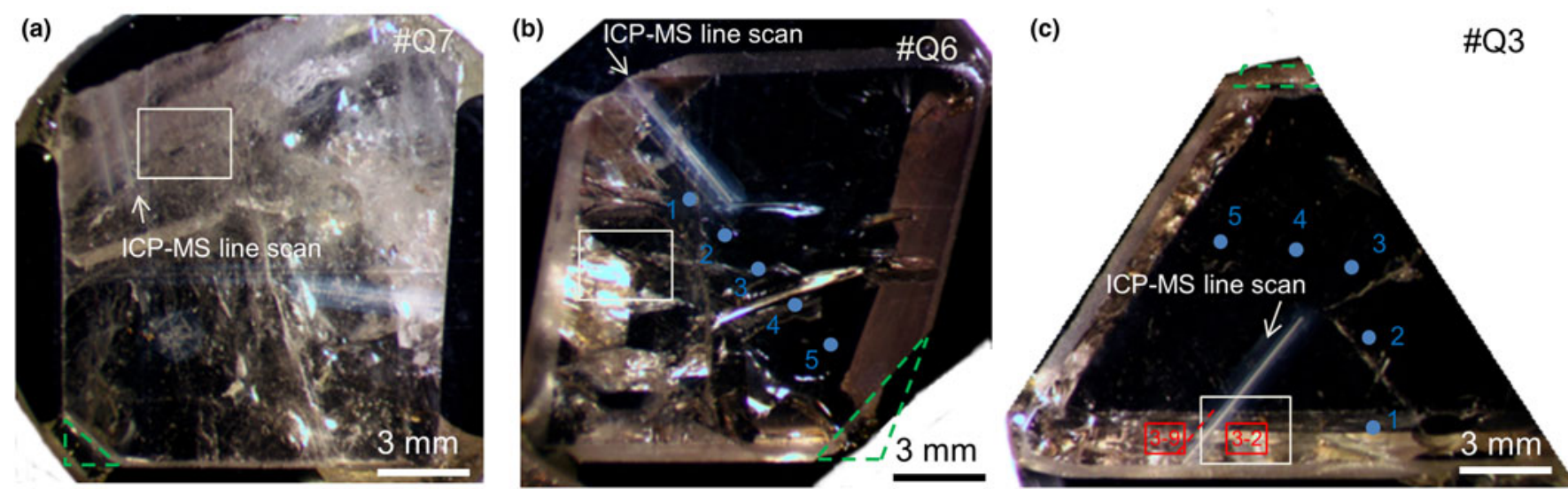

Fig. 3. Beryl samples as cut and studied from larger single crystal specimens: (a) \#Q7, (0001) faces; (b) \#Q6, (112̄1) faces; and (c) \#Q3, (1010) faces. Indicated are positions of LA-ICP-MS transects (white arrows, Fig. 7), BSE imaging (white rectangles, Fig. 7), micro-IR transects and mapping (red dashed line and rectangles, Figs. 10-12), XRD (chips cut at dashed green triangles) and EMPA (blue dots).

in size were obtained and cut into thin sections, with two samples cut parallel and four perpendicular with respect to the $c$ axis (1901B1 and 1901B2, for details see Fig. S1). Lastly several single crystals were collected from open space in veins in the northern area of Pankou (\#Q1-Q7, see Fig. S1). The different crystal faces were first studied by atomic force microscopy (AFM, AIST Inc., noncontact mode, probe tips from $\mu$ Masch Inc., spatial resolution $\sim 10 \mathrm{~nm}$ and sample scanner resolution $2 \mathrm{~nm}$ ), prior the preparation of slabs of 2-3 mm thickness for EMPA cut along different crystallographic directions perpendicular to (0001), (1010) and (1121) (\#Q7, \#Q3 and \#Q6), as shown in Fig. 3. Subsequently for IR transmission spectroscopy and imaging, the samples were thinned to $\sim 0.1 \mathrm{~mm}$ double sided polished slabs.

Micro-scale compositional mapping and quantitative microanalyses were undertaken with a JEOL JXA-8230 electron microprobe at the University of Colorado, USA (Department of Geological Sciences). It is a five-spectrometer instrument equipped with argon X-ray detectors (P-10 mixture) on spectrometer 1 and 2, and xenon X-ray detectors on spectrometers 3 to 5. Analytical conditions were $15 \mathrm{kV}$ and $20 \mathrm{nA}$ with a $5 \mu \mathrm{m}$ beam diameter (samples XBD 19-01-B1 and 17-02-B2). Background positions were chosen to avoid interferences. In order to improve precision, a few additional analyses were performed at $50 \mathrm{nA}$ and $10 \mu \mathrm{m}$ beam diameter (samples \#Q7, \#Q6 and \#Q3). The mean atomic number background correlation was used for all analyses (Donovan et al., 2016). Counting time was optimised to improve the detection limit. The ZAF matrix correction from Armstrong (1988) using the FFAST mass absorption coefficient table (Chantler et al., 2005) was applied throughout. Typical detection limits are $\sim 0.01 \mathrm{wt} . \%$ for main and minor elements.

Minor and trace elements were measured by LA-ICP-MS at the USGS Denver Federal Center, USA. Three beryl crystals with representative primary and secondary crystal phases based on the EMPA were selected. A Photon Machines Analyte G2 LA system (193 nm and $4 \mathrm{~ns}$ excimer) was coupled to a PerkinElmer DRC-e ICP-MS. Spot-lined analyses were carried out for known locations, crossing the primary and secondary phase zones. A wavelength of $193 \mathrm{~nm}$ was used. Ablation was carried out using an $80-\mu \mathrm{m}$ square spot size at $12 \mathrm{~J} / \mathrm{cm}^{2}$. Single spot analyses were ablated using 15 pulses/sec $(15 \mathrm{~Hz})$. Signals were calibrated using USGS synthetic basalt glass GSE-1g. Silicon
(29Si) was used as the internal standard element (using an average Si wt.\% content from EMPA data) for concentration calculations (Pauly, 2019).

For X-ray diffraction and structure refinement, fragments were cut from crystals \#Q3, \#Q6 and \#Q7. Single-crystal X-ray diffraction data were acquired on a Brucker P4 four-circle diffractometer (University of Colorado, USA) equipped with a point detector, an APEX II CCD detector, and a rotating Mo-anode generator operating at $50 \mathrm{kV}$ and $250 \mathrm{~mA}$. Unit-cell parameters were refined using the point-detector. The program SHELXL-97 (Sheldrick, 2008) was used to analyse the site occupancies.

Micro-Raman spectroscopy on polished sections and oriented crystals was performed on a setup (XploRA Nano, Horiba Jobin Yvon) based on a confocal Raman microscope, using $532 \mathrm{~nm}$ excitation, a $50 \times$ objective (NA $=0.5$ and focus size $\approx 1 \mu \mathrm{m}$ diameter), with power on sample of $\sim 3 \mathrm{~mW}$. Spectra are acquired using a grating of 1800 grooves $/ \mathrm{mm}$ providing for a spectral resolution of $0.5 \mathrm{~cm}^{-1}$, with a thermoelectrically cooled CCD camera. The phonon response of silicon at $520.7 \mathrm{~cm}^{-1}$ was used to calibrate the spectrometer.

Unpolarised micro-IR spectroscopy and imaging was performed in transmission, reflection and attenuated-total reflection mode (FTIR microscope LUMOS, Bruker Inc.). Background spectra were recorded before the sample measurements in air and subtracted to obtain absorbance spectra of the samples. Measurements were performed in transmission on the doublesided polished crystal slabs of $120 \mu \mathrm{m}$ thickness or less, with $50 \mu \mathrm{m}$ spatial resolution, and $2 \mathrm{~cm}^{-1}$ spectral resolution from $800 \mathrm{~cm}^{-1}$ to $6000 \mathrm{~cm}^{-1}$. Point spectra, line scans and images were acquired after EMPA and LA-ICP-MS and in areas of close proximity to correlate the $\mathrm{CO}_{2}$ and $\mathrm{H}_{2} \mathrm{O}$ IR spectra with the elemental crystal composition. For infrared peak frequencies and mode assignment see Table S2.

\section{Results}

\section{Surface texture}

Optical microscopy and AFM were used to study the beryl surface

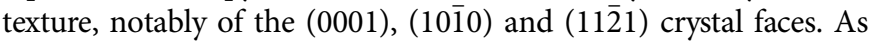
established previously (Qi et al., 2001b), the (0001) face shows hexagonal protrusions representing screw dislocations (Fig. 4a, e). 
(0001)
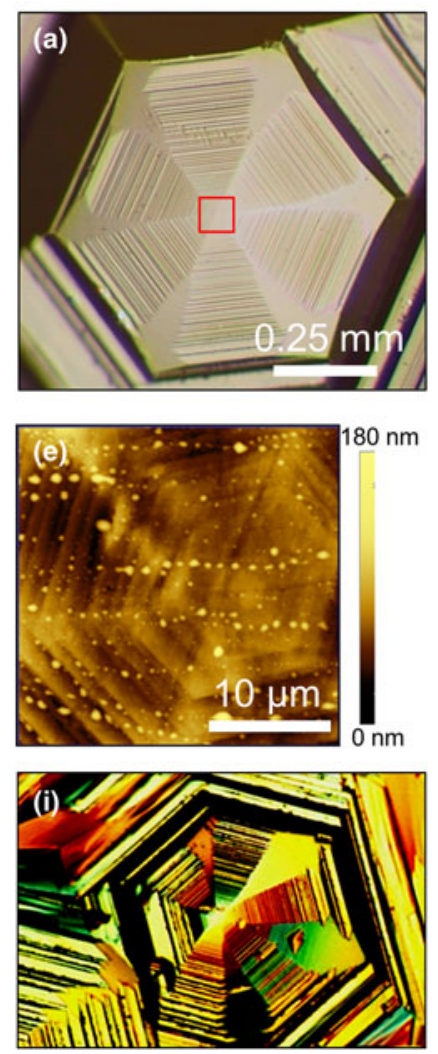

(10̄̄o)
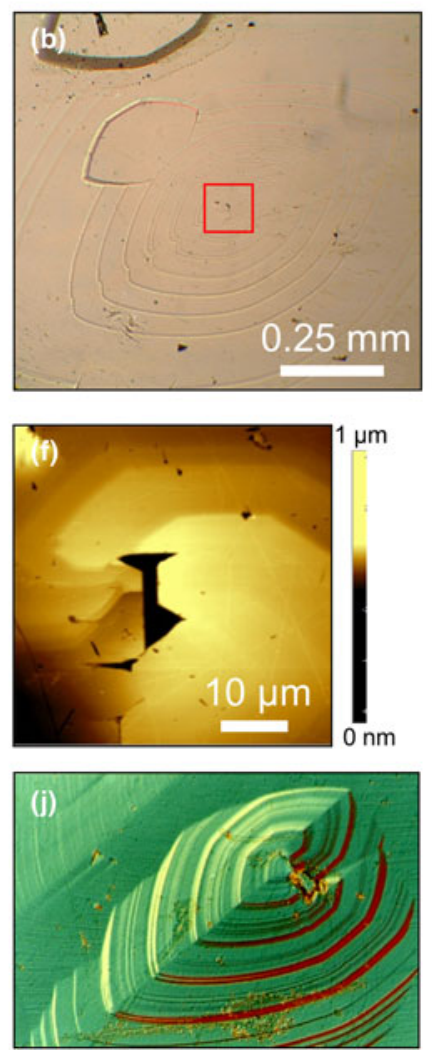

(11̄ํ1)
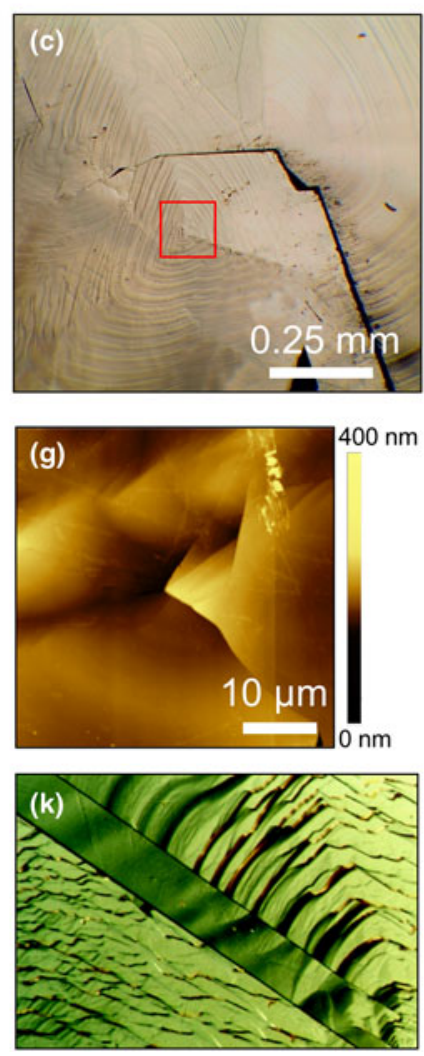

(11̄̄1)
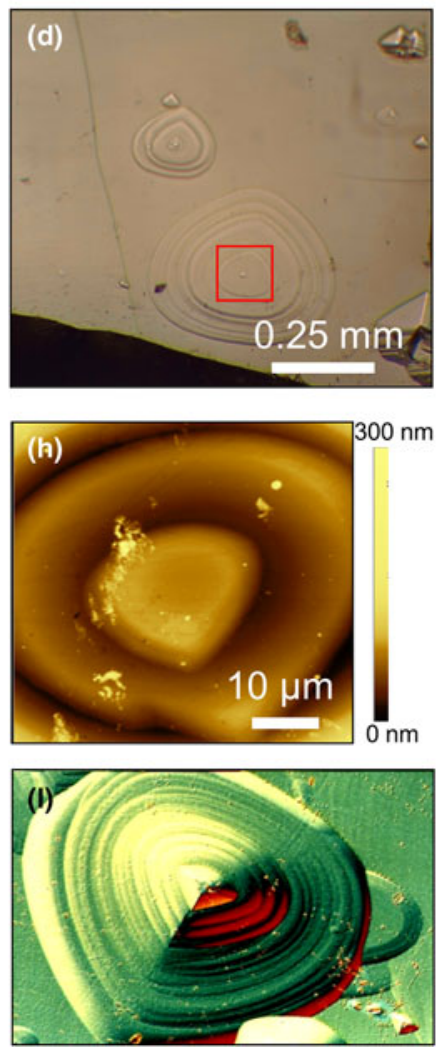

Fig. 4. Surface texture of different crystal faces of Xuebaoding beryl. (a-d) Unpolarised optical microscope images of \#Q7, \#Q3, \#Q6 and \#Q5, respectively. (e-f) AFM images of areas indicated in (a-d) (red square). (i-l) Differential interference microscope images of similar defects on corresponding faces [modified after Qi et al., 2001a]. (a, e, i) are (0001) faces, (b, f, j) are (1010) faces, and (c, d, g, h, k, l) are (11) 1$)$ faces.

Most of the hexagonal screw dislocations in (0001) display finely spaced growth steps. The (10 $\overline{1} 0)$ faces are dominated by left-handed or right-handed screw dislocations of nearly rhombohedral shape with long axis approximately parallel with respect to (0001) (Fig. 4b, f). The screw dislocations grow from the nucleation site in spirals outwards (Qi et al., 2001b). The lower density of the screw steps and kinks on (10ī0) compared to (0001) indicates a more rapid crystal growth in the (1010) lattice plane compared to (0001) leading to the tabular crystal habit (Qi et al., 2001b). In some (11 $\overline{2} 1$ ) lattice planes of beryl (Fig. 4c, g), the stacking fault defects grow layer-by-layer, until they cover the entire crystal face. Eventually, a step source that no longer disappears is formed at the protrusion of the stacking fault. The stacking fault also acts as the nucleus of the contract twin (Fig. 4k) (Qi et al., 2001b). Occasionally, dispersed heart-shaped step bunching is observed. The dislocation step spirals outwards from the protrusion and forms a closed spiral (Fig. 4d, h). A detailed future study of defects, dislocations and other structural bulk and surface features may possibly relate these features to crystal morphology and growth environment (Sunagawa, 1984; Scandale et al., 1990; Scandale and Lucchesi, 2000; Tempesta et al., 2011).

\section{Chemical composition}

Figure 5 shows optical and EMPA of the narrow vein (thin section 1702B2) containing scheelite at the schist contact and beryl in muscovite (Fig. 5a plain light, Fig. 5b UV with scheelite grain fluorescence). The beryl exhibits complex zoning as seen in the example of Fig. $5 c$ (corresponding back-scattered electron (BSE) image Fig. 5d). Quantitative compositional element mapping of $\mathrm{Al}, \mathrm{Na}, \mathrm{Fe}$ and $\mathrm{Cs}$ (Fig. 5e-h, in oxide wt.\%) indicates the negative correlation of $\mathrm{Al}$ and $\mathrm{Fe}$, representing the substitution of $\mathrm{Al}^{3+}$ for $\mathrm{M}^{2+/ 3+}$ cations, and the corresponding positive correlation of $\mathrm{Al}^{3+}$ with $\mathrm{Na}^{+}$and $\mathrm{Cs}^{+}$for charge balance.

Results of EMPA of seven representative zones averaged over three points of 1702B2 (for details see Fig. 5 and 6: low $\mathrm{Na}^{+}$, circles; high $\mathrm{Na}^{+}$, squares; intermediate $\mathrm{Na}^{+}$, triangle), as well as analyses of samples 1901B and \#Q7 (see analysis points in Figs S2, S3) are summarised in Table 1 and cover the range of compositional variations observed. $\mathrm{SiO}_{2}$ values range from 64.22 to 65.04 wt.\% (ideal 67.07 wt.\%) and $\mathrm{Al}_{2} \mathrm{O}_{3}$ values range from 17.81 to 18.55 wt.\% (ideal 18.97 wt.\%). Of the minor elements, $\mathrm{Na}_{2} \mathrm{O}$ dominates, ranging from 1.23 wt.\% up to 2.01 wt.\% and $\mathrm{Cs}_{2} \mathrm{O}$ up to 0.49 wt.\%. Iron as $\mathrm{FeO}_{\mathrm{T}}$ (total $\mathrm{Fe}$ reported as $\mathrm{FeO}$ ) ranges up to $0.50 \mathrm{wt} . \%$, and $\mathrm{MgO}$ up to 0.19 wt.\%. Traces of $\mathrm{K}^{+}, \mathrm{Ca}^{2+}, \mathrm{Ti}^{4+}$ and $\mathrm{Mn}^{2+}$ are close to the detection limit of $\sim 0.01$ wt. $\%$.

The EMPA calculations (Table 1) are based on $18 \mathrm{O}$ apfu and 3 [Be $+\mathrm{Li}$ ]. LA-ICP-MS revealed a close correlation between $\mathrm{Li}^{+}$ and $\mathrm{Na}^{+}$, allowing for the use of $\mathrm{Na}^{+}$as a proxy for $\mathrm{Li}^{+}$to a good approximation. $\mathrm{Be}^{2+}$ is thus assumed to be $3-\mathrm{Li}^{+}$. For comparison, calculations on the basis of either $18 \mathrm{O}$ and $3 \mathrm{Be}$, or $6 \mathrm{Si}$ are shown in Table S3 and S4, respectively (Groat et al., 2008; Fridrichová et al., 2016; Lum et al., 2016). 

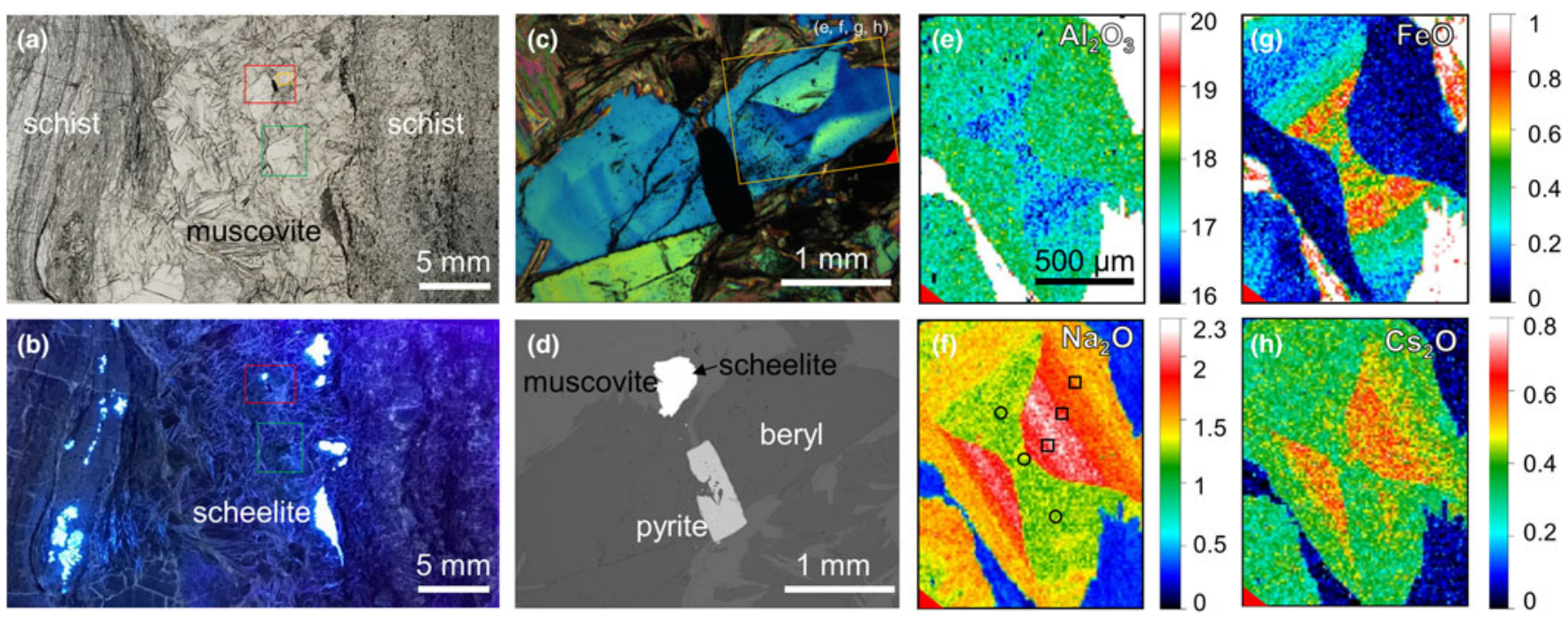

Fig. 5. Narrow vein of muscovite in schist with scheelite and beryl (thin section 1702B2): (a) plane light; (b) UV light; (c) beryl under crossed polarised light (red area from a); (d) corresponding BSE image. Quantitative EMPA mapping (scale bar oxide wt.\%) of $\mathrm{Al}_{2} \mathrm{O}_{3}(\mathrm{e}), \mathrm{Na}_{2} \mathrm{O}(\mathrm{f})$, $\mathrm{FeO}(\mathrm{g})$ and $\mathrm{Cs}_{2} \mathrm{O}(\mathrm{h})$ of yellow region indicated in (c) with zoning and coupled substitution. Data for EMP point analyses (open circles and squares in (f)) in Table 1 . For BSE and EMPA data of second area (green rectangles in (a) and (b)) see Fig. 6.

With $\mathrm{Si}^{4+}$ ranging from 5.978 to 5.994 apfu this indicates almost full $6 \mathrm{Si}$ T1 site occupation without $\mathrm{Si}-\mathrm{Al}$ substitution. $\mathrm{Na}^{+}$ranges from 0.20 to $0.36 \mathrm{apfu}$, which is much higher than $\mathrm{Mg}^{2+}$ (up to 0.027), $\mathrm{K}^{+}$(0.001-0.004), $\mathrm{Cs}^{+}$(0.004-0.019), $\mathrm{Ca}^{2+}$ $(<0.002), \mathrm{Ti}^{4+}(<0.002), \mathrm{Fe}^{3+}$ (up to 0.034) and $\mathrm{Mn}^{2+}(<0.002)$. $\mathrm{Na}^{+}$typically occupies the channel site to balance the charge difference by coupled substitution.

Data from LA-ICP-MS was used to determine $\mathrm{Li}^{+}$and other minor and trace elements. Representative results of LA-ICP-MS line scans in samples \#Q7, \#Q6 and \#Q3 are shown in Figure 7, highlighting regions of primary concentric zoning dissected by secondary veinlets (\#Q7, Fig. 7a), typical primary concentric zoning (\#Q6, Fig. 7b), or irregular but zoned regions near a crystal surface (\#Q3, Fig. 7c), with corresponding LA-ICP-MS transects (Fig. $7 \mathrm{~d}-\mathrm{f}$ ) as indicated. A characteristic and correlated increase in $\mathrm{Na}^{+}$and $\mathrm{Li}^{+}$is observed in the secondary phases, with corresponding depletion in $\mathrm{K}^{+}, \mathrm{Rb}^{+}, \mathrm{Cs}^{+}, \mathrm{Mg}^{2+}, \mathrm{Mn}^{2+}$ and $\mathrm{Fe}^{3+}$. This effect is reflected in the BSE contrast in primary as well as secondary growth darker areas corresponding to greater light element content of $\mathrm{Li}^{+}$and $\mathrm{Na}^{+}$, with depletion in the heavy elements.

Representative quantitative LA-ICP-MS results are listed in Table 2, with calculated apfu values based on assuming $6 \mathrm{Si}$. Consistent with EMPA results, $\mathrm{Na}^{+}$ranges from 0.25 to $0.37 \mathrm{apfu}$, compared to minor $\mathrm{Cs}^{+}(0.0035-0.016), \mathrm{Mg}^{2+}(0.000-0.017)$, $\mathrm{Fe}^{3+}(0.000-0.015)$ and only traces of other elements. In the primary zones, $\mathrm{Na}^{+}(0.246-0.268)$ is considerably less than in the secondary zones $(0.354-0.371)$, yet correlated closely with the amount of $\mathrm{Li}^{+}$in primary $(0.254-0.272)$ and secondary beryl (0.347-0.368).

In summary, these results show the presence of only a weak $\mathrm{Al}^{3+}$ A-site for $2+$ cations substitution vector, but a dominating $\mathrm{Li}^{+} \mathrm{T} 2$-site for $\mathrm{Be}^{2+}$ substitution vector (see discussion below).

\section{Crystallography and structure refinement}

The refined crystal structure parameters as well as data collection parameters, are summarised in Table 3 . The unit-cell parameters were refined from centring angles of 60 strong reflections with two between 10 and $28^{\circ}$ using a point detector system on a Bruker P4 diffractometer. The $a$-axis values of the lattice range from $9.2161(2)$ to $9.2171(4) \AA$, while $c$-axis values range from $9.2178(2)$ to $9.2219(4) \AA$, and the unit-cell volume ranges from $678.03(3)$ to $678.48(7) \AA^{3}$. The $c / a$ ratio ranges from 1.0002 to 1.0005 and is consistent with T2 type beryl, with the unit-cell controlled primarily by $\mathrm{Be}^{2+}$ substitution (Aurisicchio et al., 1988, 1994). Intensity data were measured using a Bruker APEX II CCD detector out to a two-theta angle of $\sim 80^{\circ}$ (Table 3). Atom position, displacement parameters and cation occupancies were refined using SHELXL (Sheldrick, 2008) based on ionised atom scattering factors for cations (Cromer and Mann, 1968) and $\mathrm{O}^{-2}$ (Azavant and Lichanot, 1993). Atom position, displacement and occupancy parameters are given in Supplementary Table S5. The crystallographic information files have been deposited with the Principal Editor of Mineralogical Magazine and are available as Supplementary material (see below).

Selected bond distances derived from refinements using ionised-atom scattering factors are shown in Table 4 (Guo et al., 2000a; Robinson et al., 1971) (further details and atomic position coordinates and anisotropic displacement parameters are listed in Table S5). Here, O1 indicates oxygen linked with $\mathrm{Si}$, whereas $\mathrm{O} 2$ indicates the oxygen shared by $\mathrm{Si}, \mathrm{Al}$ and $\mathrm{Be}$. $\mathrm{Si}-\mathrm{O}$ has the shortest (1.61 $\AA$ ) while Al-O has the longest bond length (1.91 $\AA$ ).

The derived crystal structure is shown in Fig. 8a (projected onto (0001)) and Fig. $8 \mathrm{~b}$ with its edge-linked distorted tetrahedrally coordinated $\mathrm{T} 2(\mathrm{Be})$ and octahedrally coordinated $\mathrm{A}(\mathrm{Al})$ sites. Crystal channels are characterised by the wide $\mathrm{C} 1 / 2 \mathrm{a}$ site between the rings and narrow $\mathrm{C} 2 / 2 \mathrm{~b}$ site of the interior of the tetrahedral $\left[\mathrm{Si}_{6} \mathrm{O}_{18}\right]^{12-}$ ring with diameters of $\sim 5.2 \AA$ and $\sim 2.6 \AA$, respectively. Figure $8 \mathrm{c}$ shows $\mathrm{C} 2$ site occupation with $\mathrm{Na}^{+}$and associated type IId, IIs and I water configurations, with the distinct coordination of two water molecules to $\mathrm{Na}^{+}$ (type IId), one water molecule and optionally $\mathrm{C} 1$ site occupation with $\mathrm{CO}_{2}$ (type IIs), or the alkali cation free-water configuration (type I) (Fridrichová et al., 2016). 

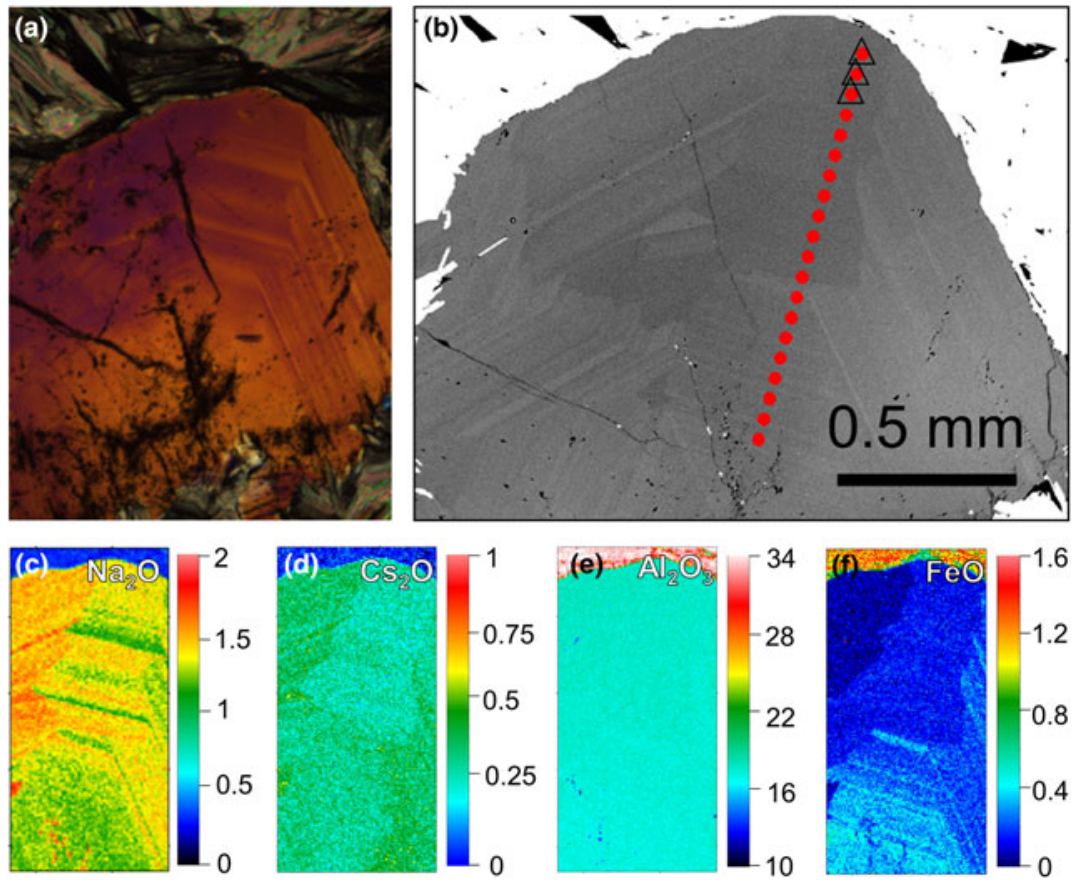

Fig. 6. Concentric zoning of beryl of thin section sample 1702B2 (green rectangle in Fig. $5 a$ and $5 b$ ). (a) Optical microscope image under crossed polarisation; and (b) BSE image with EMPA transect (red dots), triangles indicate the selected EMPA points listed in Table 1. (c-f) Quantitative mapping of selected area for $\mathrm{Na}_{2} \mathrm{O}, \mathrm{Cs}_{2} \mathrm{O}, \mathrm{Al}_{2} \mathrm{O}_{3}$ and $\mathrm{FeO}$, respectively (scale bar oxide wt.\%).
Generally similar site occupancy values for the different lattice sites are found for all three crystals analysed. The A, T1 and T2 sites are almost fully occupied. The site population calculation is in good agreement with the EMPA and LA-ICP-MS data with a significant $\mathrm{Li}^{+}$substitution for $\mathrm{Be}^{2+}$ (T2) and minor $M^{2+}$ substitution for $\mathrm{Al}^{3+}(\mathrm{A})$, charge balanced predominantly by $\mathrm{Na}^{+}$as the only alkali occupying the small C2 site, and the larger alkali $\left(\mathrm{K}^{+}, \mathrm{Cs}^{+}, \mathrm{Rb}^{+}\right)$and $\mathrm{Fe}^{2+/ 3+}$ together with water and minor $\mathrm{CO}_{2}$ on the $\mathrm{C} 1$ site.

\section{Raman spectroscopy}

Representative polarisation-resolved Raman spectra, reflecting the different crystal orientations and type I and II water orientation, are shown in Fig. 9. Here, $E_{\text {inc }}$ and $E_{\mathrm{R}}$ represent incident fundamental pump polarisation and Raman scattered polarisation, respectively. All spectra of different sample locations have negligible background indicating high structural integrity and overall low defect/inclusion density. The peaks below $1400 \mathrm{~cm}^{-1}$ are associated with beryl lattice phonon modes (For Raman peak frequencies and mode assignment see Table S6 (Kim et al., 1995; Qi et al., $2001 \mathrm{~b}$ ). The strong peaks at $685 \mathrm{~cm}^{-1}$ and $1066 \mathrm{~cm}^{-1}$ are due to $\mathrm{Si}-\mathrm{O}$ vibrations. The modes at $322 \mathrm{~cm}^{-1}$ and $396 \mathrm{~cm}^{-1}$ are $\mathrm{Al}-\mathrm{O}$ bands. The two bands at $524 \mathrm{~cm}^{-1}$ and $1009 \mathrm{~cm}^{-1}$ represent Be$\mathrm{O}$ vibrations. In the water stretch region the two and only partially resolved peaks are due to type II $\left(3594 \mathrm{~cm}^{-1}\right)$ and type I $\left(3604 \mathrm{~cm}^{-1}\right)$ water.

The non-degenerate symmetry modes $\left(A_{1 g}\right)$ which have the strongest Raman response are shown in Fig. 9a, b. The doubly degenerate symmetry modes $\left(\mathrm{E}_{1 \mathrm{~g}}\right)$ are presented in Fig. $9 \mathrm{c}, \mathrm{d}$. The Raman emission of water, polarised perpendicular with respect to the $c$ axis of beryl, is weak when the incident field is polarised parallel with respect to the $c$ axis, as expected and shown in Fig. 9d. Doubly degenerate symmetric modes $\mathrm{E}_{2 \mathrm{~g}}$ are presented in Fig. 9e, f, in which $398 \mathrm{~cm}^{-1}$ and $684 \mathrm{~cm}^{-1}$ are due to $\mathrm{Si}-\mathrm{O}$ and $\mathrm{Al}-\mathrm{O}$ vibrations, respectively, and with a corresponding water peak (Kim et al., 1995; Hagemann et al., 1990). The combination of Fig. $9 \mathrm{~b}$ and $9 \mathrm{f}$ confirm the expected molecular orientation of type I and type IIs water (Hagemann et al., 1990). Type I is expected to be more polarisable along the $c$ axis, and thus stronger in Fig. 9b, while type II is expected to be more polarisable perpendicular with respect to the $c$ axis and thus stronger in the polarisation combination of Fig. 9f, as observed. Polarised Raman spectra with the incident wave vector perpendicular with respect to the (10ī0) face and unpolarised Raman spectra are shown in Fig. S4.

\section{Micro-IR spectroscopy and mapping of water content}

A representative IR point spectrum is shown in Fig. 10 from (a) transect \#Q3-7 and (b) acquired parallel with respect to the LA-ICP-MS line on \#Q3 in Fig. 7 (see also inset Fig. 10b). Infrared peak frequencies and mode assignments are listed in Table S2 (Charoy et al., 1996; Qi et al., 2001d; Łodziński et al., 2005; Adamo et al., 2008; Della Ventura et al., 2015; Mashkovtsev et al., 2016). The spectrally narrow bending $\left(v_{2}^{\mathrm{I}}\right)$ and asymmetric stretch $\left(v_{3}^{\mathrm{I}}\right)$ of type I $\left(1600\right.$ and $\left.3694 \mathrm{~cm}^{-1}\right)$, bending $\left(v_{2}^{\text {IIs }}\right)$ and symmetric stretch $\left(v_{1}^{\text {IIs }}\right)$ of type IIs water $\left(1637\right.$ and $\left.3588 \mathrm{~cm}^{-1}\right)$, and asymmetric $\mathrm{CO}_{2}$ stretch $\left(2358 \mathrm{~cm}^{-1}\right)$ modes can be discerned. The broad peak at $\sim 1950 \mathrm{~cm}^{-1}$ has been assigned to the overtone absorption of a lattice phonon mode (Charoy et al., 1996). The detailed transects for the type I and II stretch modes in Fig. 10b show an inversion in relative type I and II water content at the transition from primary to secondary beryl. Further, the type II peak is split as seen in the magnified region of Fig. $10 \mathrm{c}$, with the main peak $v_{1}^{\text {IIs }}$ at $\sim 3588 \mathrm{~cm}^{-1}$ corresponding to type IIs, and the shoulder at $\sim 3605 \mathrm{~cm}^{-1}$ corresponding probably to a combination of the symmetric stretches of type I $\left(v_{1}^{\mathrm{I}}\right)$ and type II water $\left(v_{1}^{\mathrm{IId}}\right)$. The minor peak at about $3651 \mathrm{~cm}^{-1}$ is due to the antisymmetric stretch of type IIs water $\left(v_{3}^{\text {IIs }}\right)$.

To determine relative peak intensities, the spectra have been fitted using simple Lorentzian lineshapes, with 5-6 peaks (dashed lines in Fig. 10c, see also supplement Fig. S5), with centre 
Table 1. Quantitative elements content obtained by EMPA for thin sections (TS) and single crystals (SC)*

\begin{tabular}{|c|c|c|c|c|c|c|c|c|}
\hline \multicolumn{2}{|c|}{ Sample number } & \multirow{2}{*}{$\begin{array}{c}\# 1702 \mathrm{~B} 2 \\
\mathrm{TS} \\
\text { Low-Na O }\end{array}$} & \multirow{2}{*}{$\begin{array}{c}\# 1702 \mathrm{~B} 2 \\
\text { TS } \\
\text { High-Na } \square\end{array}$} & \multirow{2}{*}{$\begin{array}{c}\# 1702 B 2 \\
\text { TS } \\
\text { Int.- Na } \triangle\end{array}$} & \multirow{2}{*}{ 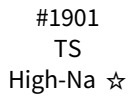 } & \multirow{2}{*}{$\begin{array}{c}\# 1901 \\
\text { TS } \\
\text { Low-Na } \diamond\end{array}$} & \multirow{2}{*}{$\begin{array}{c}\text { \#Q7 } \\
\text { SC } \\
\text { Low-Na }\end{array}$} & \multirow{2}{*}{$\begin{array}{c}\text { \#Q7 } \\
\text { SC } \\
\text { High-Na }\end{array}$} \\
\hline Wt.\% oxide & Ideal crystal & & & & & & & \\
\hline $\mathrm{Na}_{2} \mathrm{O}$ & - & 1.231 & 1.690 & 1.338 & 2.005 & 1.130 & 1.422 & 1.719 \\
\hline MgO & - & 0.193 & 0.026 & 0.025 & 0.033 & 0.064 & 0.179 & 0.001 \\
\hline $\mathrm{K}_{2} \mathrm{O}$ & - & 0.020 & 0.029 & 0.018 & 0.005 & 0.010 & 0.035 & 0.007 \\
\hline $\mathrm{Cs}_{2} \mathrm{O}$ & - & 0.416 & 0.481 & 0.315 & 0.152 & 0.389 & 0.486 & 0.093 \\
\hline $\mathrm{CaO}$ & - & 0.004 & 0.016 & 0.005 & - & 0.001 & - & - \\
\hline $\mathrm{TiO}_{2}$ & - & 0.032 & - & 0.005 & - & 0.010 & - & 0.004 \\
\hline $\mathrm{FeO}$ & - & 0.495 & 0.067 & 0.139 & 0.013 & 0.235 & 0.170 & - \\
\hline $\mathrm{MnO}$ & - & 0.026 & - & 0.005 & 0.000 & 0.021 & - & - \\
\hline $\mathrm{SiO}_{2}$ & 67.07 & 64.668 & 64.479 & 64.507 & 64.360 & 64.841 & 64.705 & 64.914 \\
\hline $\mathrm{Al}_{2} \mathrm{O}_{3}$ & 18.97 & 17.810 & 18.307 & 18.210 & 18.481 & 18.366 & 18.079 & 18.516 \\
\hline $\mathrm{Li}_{2} \mathrm{O}_{\text {cal }}$ & & 0.594 & 0.815 & 0.645 & 0.967 & 0.545 & 0.685 & 0.829 \\
\hline $\mathrm{BeO}_{\mathrm{cal}}$ & 13.96 & 12.481 & 12.088 & 12.365 & 11.827 & 12.628 & 12.336 & 12.150 \\
\hline $\begin{array}{l}\text { Total } \\
\text { apfu }\end{array}$ & 100.00 & 97.969 & 97.999 & 97.578 & 97.843 & 98.243 & 98.098 & 98.234 \\
\hline $\mathrm{Na}$ & - & 0.221 & 0.304 & 0.241 & 0.361 & 0.202 & 0.255 & 0.307 \\
\hline $\mathrm{Mg}$ & - & 0.027 & 0.004 & 0.004 & 0.005 & 0.009 & 0.025 & 0.000 \\
\hline K & - & 0.002 & 0.003 & 0.002 & 0.001 & 0.001 & 0.004 & 0.001 \\
\hline Cs & - & 0.016 & 0.019 & 0.012 & 0.006 & 0.015 & 0.019 & 0.004 \\
\hline $\mathrm{Ca}$ & - & 0.000 & 0.002 & 0.001 & 0.000 & 0.000 & - & - \\
\hline $\mathrm{Ti}$ & - & 0.002 & 0.000 & 0.000 & 0.000 & 0.001 & - & 0.000 \\
\hline $\mathrm{Fe}$ & - & 0.034 & 0.005 & 0.010 & 0.001 & 0.016 & 0.012 & - \\
\hline $\mathrm{Mn}$ & - & 0.002 & - & 0.000 & 0.000 & 0.002 & 0.000 & - \\
\hline $\mathrm{Si}$ & 6 & 5.994 & 5.986 & 5.992 & 5.978 & 5.980 & 5.993 & 5.989 \\
\hline $\mathrm{Al}$ & 2 & 1.945 & 2.003 & 1.993 & 2.023 & 1.996 & 1.973 & 2.013 \\
\hline $\mathrm{Li}_{\text {fixed }}$ & & 0.221 & 0.304 & 0.241 & 0.361 & 0.202 & 0.255 & 0.307 \\
\hline $\mathrm{Be}_{\mathrm{cal}}$ & 3 & 2.779 & 2.696 & 2.759 & 2.639 & 2.798 & 2.745 & 2.693 \\
\hline
\end{tabular}

*Every value represents the average of three analyses. The measured points for $\bigcirc$ and $\square$ are shown in Fig. 5, $\triangle$ is shown in Fig. 6 , $\downarrow$ and $\diamond$ are shown in Fig. S2. -: close or below the detection limit.

$\mathrm{Li}_{\text {fixed }}$ : Li set to the Na value based on correlation derived from LA-ICP-MS; 'cal': calculated value, $\mathrm{Be}_{\text {cal }}=3-\mathrm{Li}$.

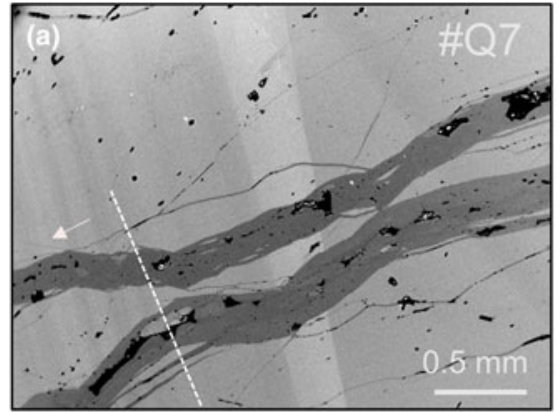

(d)

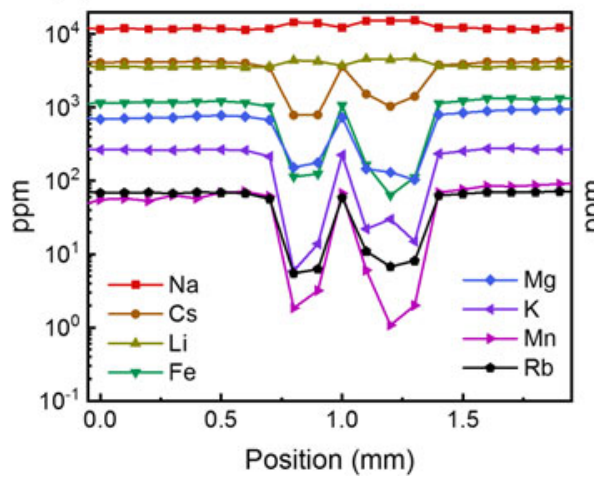

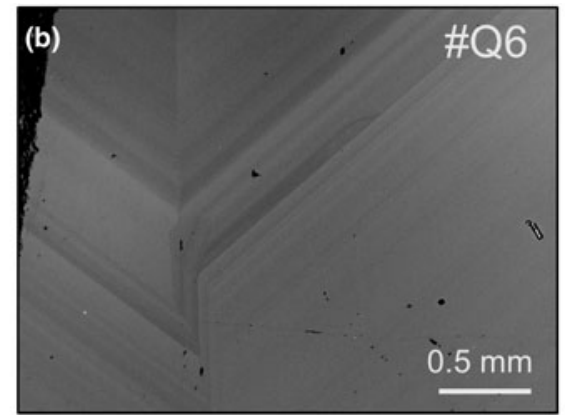

(e)

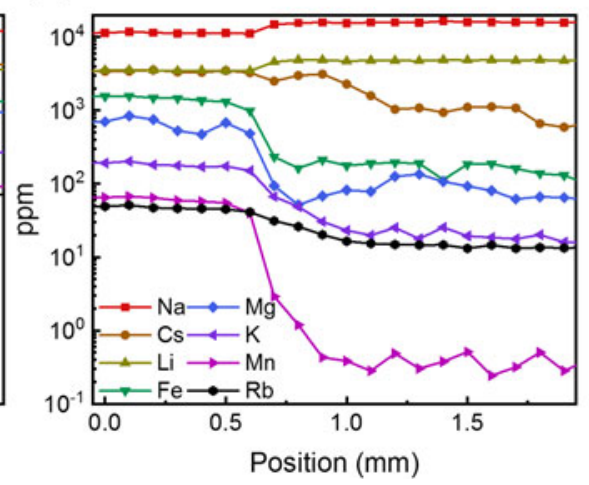

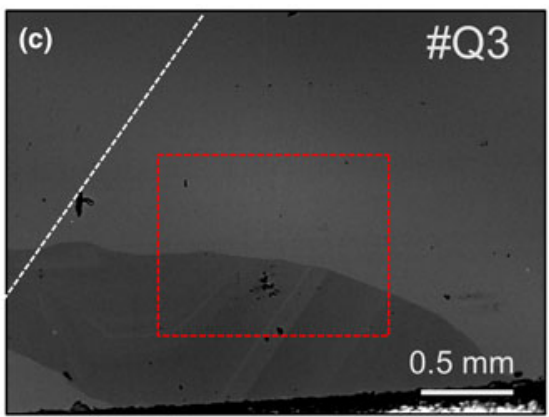

(f)

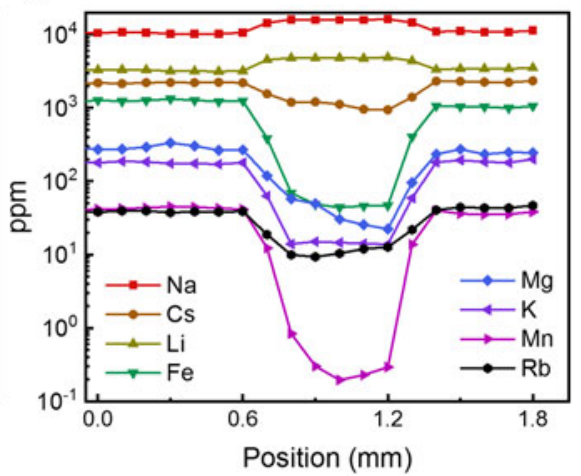

Fig. 7. Representative BSE images of single crystal samples \#Q7 (a), \#Q6 (b) and \#Q3 (c), with LA-ICP-MS transects (d-f, dashed lines in (a) and (c)): transect (d) location is $\sim 0.3 \mathrm{~mm}$ just left of field of view in (a) at extension of meandering secondary feature. Transect (e) is not related to (b) with location indicated in Fig. $3 b$. Transect (f) shown in (c) as indicated, the full position is shown in inset of Fig. 10b. The LA-ICP-MS elemental pattern reflects primary and secondary beryl phases, with characteristic positive correlation of $\mathrm{Na}$ and $\mathrm{Li}$, both negatively correlated with all other trace elements. Area in (c) (red dashed rectangle) indicates micro-IR mapping \#Q3-2 as shown in Fig. 12. 
Table 2. Representative minor- and trace-element composition of beryl determined by LA-ICP-MS.*

\begin{tabular}{|c|c|c|c|c|c|c|}
\hline ppm & \#Q7-3 S & \#Q7-3 P & \#Q6-1 S & \#Q6-1 P & \#Q3-1 S & \#Q3-1 P \\
\hline $\mathrm{Li}$ & 4611.20 & 3498.59 & 4462.00 & 3433.05 & 4732.43 & 3264.07 \\
\hline $\mathrm{Na}$ & $15,179.02$ & $11,414.04$ & $15,069.01$ & $11,269.89$ & $15,795.65$ & $10,484.95$ \\
\hline $\mathrm{Mg}$ & 145.29 & 750.37 & 327.22 & 720.82 & 25.57 & 293.78 \\
\hline$P$ & 27.76 & 16.01 & 28.83 & 11.66 & 14.79 & 15.90 \\
\hline$S$ & 73.57 & 66.73 & 50.84 & 54.80 & 44.67 & 47.49 \\
\hline K & 22.02 & 260.59 & 37.25 & 194.15 & 14.09 & 183.23 \\
\hline $\mathrm{Ca}$ & 18.60 & 53.72 & 16.46 & 70.35 & 21.92 & 75.41 \\
\hline $\mathrm{Ti}$ & 35.68 & 20.70 & 20.02 & 3.36 & 5.92 & 11.15 \\
\hline $\mathrm{Mn}$ & 6.02 & 71.22 & 0.21 & 66.12 & 0.23 & 39.11 \\
\hline $\mathrm{Fe}$ & 165.55 & 1157.46 & 40.43 & 1550.04 & 45.93 & 1167.36 \\
\hline$Z n$ & 6.74 & 54.53 & 1.17 & 49.13 & 13.28 & 58.39 \\
\hline $\mathrm{Ga}$ & 11.82 & 29.84 & 15.52 & 14.90 & 29.69 & 10.88 \\
\hline $\mathrm{Rb}$ & 10.92 & 67.63 & 11.16 & 49.83 & 11.96 & 37.98 \\
\hline Cs & 1520.71 & 4019.28 & 870.63 & 3170.35 & 958.81 & 2080.47 \\
\hline \multicolumn{7}{|l|}{ Apfu } \\
\hline $\mathrm{Li}$ & 0.3589 & 0.2723 & 0.3473 & 0.2672 & 0.3683 & 0.2540 \\
\hline $\mathrm{Na}$ & 0.3566 & 0.2682 & 0.3540 & 0.2648 & 0.3711 & 0.2463 \\
\hline $\mathrm{Mg}$ & 0.0032 & 0.0167 & 0.0073 & 0.0160 & 0.0006 & 0.0065 \\
\hline$P$ & 0.0005 & 0.0003 & 0.0005 & 0.0002 & 0.0003 & 0.0003 \\
\hline$S$ & 0.0012 & 0.0011 & 0.0009 & 0.0009 & 0.0008 & 0.0008 \\
\hline K & 0.0003 & 0.0036 & 0.0005 & 0.0027 & 0.0002 & 0.0025 \\
\hline $\mathrm{Ca}$ & 0.0003 & 0.0007 & 0.0002 & 0.0009 & 0.0003 & 0.0010 \\
\hline $\mathrm{Ti}$ & 0.0004 & 0.0002 & 0.0002 & 0.0000 & 0.0001 & 0.0001 \\
\hline $\mathrm{Mn}$ & 0.0001 & 0.0007 & 0.0000 & 0.0007 & 0.0000 & 0.0004 \\
\hline $\mathrm{Fe}$ & 0.0016 & 0.0112 & 0.0004 & 0.0150 & 0.0004 & 0.0113 \\
\hline $\mathrm{Zn}$ & 0.0001 & 0.0005 & 0.0000 & 0.0004 & 0.0001 & 0.0005 \\
\hline $\mathrm{Ga}$ & 0.0001 & 0.0002 & 0.0001 & 0.0001 & 0.0002 & 0.0001 \\
\hline $\mathrm{Rb}$ & 0.0001 & 0.0004 & 0.0001 & 0.0003 & 0.0001 & 0.0002 \\
\hline Cs & 0.0062 & 0.0163 & 0.0035 & 0.0129 & 0.0039 & 0.0085 \\
\hline
\end{tabular}

${ }^{\star} \mathrm{S}$ indicates the secondary phase of beryl while $\mathrm{P}$ indicates the primary phase.

Table 3. Crystal structure refinement parameters for beryl from Xuebaoding (\#Q7, \#Q6, and \#Q3) compared to reported data.

\begin{tabular}{|c|c|c|c|c|}
\hline & \#Q7 & \#Q6 & \#Q3 & Reported data ${ }^{a}$ \\
\hline$a(\AA)$ & $9.2161(2)^{b}$ & $9.2162(2)^{b}$ & $9.2171(4)^{b}$ & $9.209(2)$ \\
\hline$c(\AA)$ & $9.2178(2)^{b}$ & $9.2182(2)^{b}$ & $9.2219(4)^{b}$ & $9.2221(9)$ \\
\hline$V\left(\AA^{3}\right)$ & $678.03(3)$ & $678.08(3)$ & $678.48(7)$ & $677.4(2)$ \\
\hline Space group & $P 6 / m c c$ & $P 6 / m c c$ & $P 6 / m c c$ & $P 6 / m c c$ \\
\hline$Z$ & 2 & 2 & 2 & 2 \\
\hline Radiation & MoK $\alpha$ & MoK $\alpha$ & MoK $\alpha$ & MoK $\alpha$ \\
\hline $2 \theta$ range $\left({ }^{\circ}\right)$ & $0-80.77$ & $0-80.59$ & $0-80.76$ & $5.1-49.98$ \\
\hline Reflections measured & 41515 & 77872 & 77620 & - \\
\hline Unique reflections & 767 & 762 & 767 & 775 \\
\hline$R(\sigma)$ & 0.0104 & 0.0099 & 0.0130 & - \\
\hline$R_{\text {int }}$ & 0.0384 & 0.0350 & 0.0395 & 0.0352 \\
\hline$R_{1}$ & $0.0249^{c}$ & $0.0268^{c}$ & $0.0295^{c}$ & 0.0371 \\
\hline
\end{tabular}

${ }^{\mathrm{a}}$ Guo et al. (2000).

bunit cell refinement obtained from point detector data.

'Using ionised atom scattering factors for cations (Cromer and Mann, 1968) and for $\mathrm{O}^{2-}$ (Azavant and Lichanot, 1993).

frequencies of $v_{1}^{\text {IIs }}$ and $v_{3}^{\mathrm{I}}$ of $3588 \mathrm{~cm}^{-1}$ and $3694 \mathrm{~cm}^{-1}$, respectively. The frequencies vary by less than $\pm 1 \mathrm{~cm}^{-1}$ between primary and secondary crystal phases.

The spatial variation of the relative IR peak absorption for type I and IIs water and $\mathrm{CO}_{2}$ across the primary and secondary phase is shown in Fig. 11a. The increase in spectral intensity of $v_{1}^{\text {IIs }}$ (orange) is observed in the secondary phase (1.0 to $1.7 \mathrm{~mm}$ ), while $v_{3}^{\mathrm{I}}$ (brown) decreases. The mixed shoulder at $\sim 3605 \mathrm{~cm}^{-1}$ (black) correlates with the $v_{3}^{\mathrm{I}}$ intensity, suggesting that it is associated primarily with $v_{1}^{\mathrm{I}}$. Additionally, the $\mathrm{CO}_{2}$ stretch (purple) slightly decreases in the secondary phase.
Table 4. Selected interatomic distances ( $\AA$ ) for beryl from Xubaoding in comparison to reported data.

\begin{tabular}{|c|c|c|c|c|}
\hline & $\#$ Q7 & \#Q6 & $\#$ Q3 & Reported data ${ }^{a}$ \\
\hline \multicolumn{5}{|l|}{ Be tetrahedron (T2) } \\
\hline $\mathrm{Be}-02(4)$ & $1.6656(6)$ & $1.6659(8)$ & $1.6655(7)$ & $1.6722(5)$ \\
\hline Polyhedral volume $\left(\AA^{3}\right)$ & 2.0811 & 2.0825 & 2.0790 & - \\
\hline Quadratic elongation ${ }^{\mathrm{b}}$ & 1.0909 & 1.0908 & 1.0915 & - \\
\hline \multicolumn{5}{|l|}{ Al octahedron (A) } \\
\hline $\mathrm{Al}-02(6)$ & $1.9094(6)$ & $1.9097(7)$ & $1.9095(6)$ & $1.9065(6)$ \\
\hline Polyhedral volume $\left(\AA^{3}\right)$ & 9.0066 & 9.0111 & 9.0092 & - \\
\hline Quadratic elongation & 1.0202 & 1.0202 & 1.0202 & - \\
\hline \multicolumn{5}{|l|}{ Si tetrahedron (T1) } \\
\hline $\mathrm{Si}-01$ & $1.6017(8)$ & $1.6021(10)$ & $1.6010(9)$ & $1.5985(7)$ \\
\hline $\mathrm{Si}-01$ & $1.6044(8)$ & $1.6046(10)$ & $1.6049(9)$ & $1.6054(6)$ \\
\hline $\mathrm{Si}-\mathrm{O} 2(2)$ & $1.6153(6)$ & $1.6149(7)$ & $1.6164(7)$ & $1.6118(5)$ \\
\hline Average $\mathrm{Si}-\mathrm{O}$ & 1.6092 & 1.6092 & 1.6097 & 1.6052 \\
\hline Polyhedral volume $\left(\AA^{3}\right)$ & 2.1337 & 2.1334 & 2.1359 & - \\
\hline Quadratic elongation & 1.0015 & 1.0016 & 1.0015 & - \\
\hline \multicolumn{5}{|l|}{ Na channel (C2) } \\
\hline $\mathrm{Na}$-water (2) & $2.3044(0)$ & $2.3045(0)$ & $2.3055(1)$ & - \\
\hline $\mathrm{Na}-\mathrm{O} 1(6)$ & $2.5561(10)$ & $2.5547(12)$ & $2.5577(11)$ & $2.553(0)$ \\
\hline Polyhedral volume $\left(\AA^{3}\right)$ & 26.078 & 26.050 & 26.1223 & - \\
\hline
\end{tabular}

${ }^{\mathrm{a}}$ Guo et al. (2000); ${ }^{\mathrm{b}}$ Robinson et al. (1971)

The corresponding absolute amount of water can be estimated based on the Lambert-Beer law $A=\varepsilon c d$, where $A$ is the absorbance, $\varepsilon$ the molar absorption coefficient $(\mathrm{L} / \mathrm{mol} \cdot \mathrm{cm}), c$ the water concentration $(\mathrm{mol} / \mathrm{L})$, and $d$ the sample thickness $(\mathrm{cm})$ (Fukuda et al., 2009). In our case, the sample thickness of \#Q3 is $\sim 120 \mu \mathrm{m}$. We use reported molar absorption coefficients of type I $\left(3696 \mathrm{~cm}^{-1}\right)$ and type IIs $\left(3588 \mathrm{~cm}^{-1}\right)$ water modes of $\varepsilon_{\mathrm{I}}=197 \mathrm{~L} / \mathrm{mol} \cdot \mathrm{cm}$ 


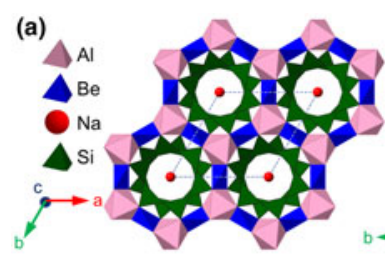

(c)
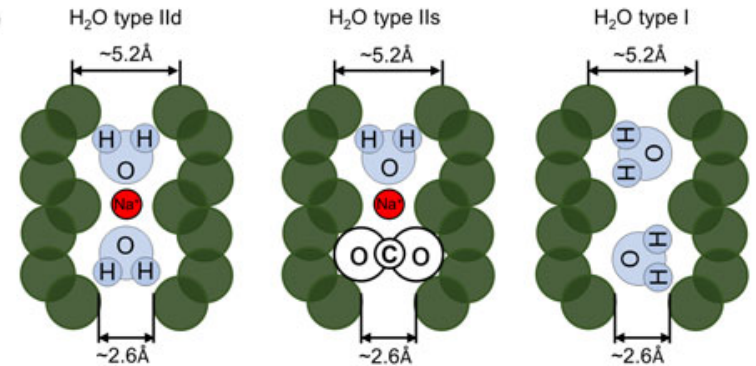

Fig. 8. Crystal structure of beryl. (a) Along orientation parallel with respect to the $c$ axis; (b) perpendicular with respect to the $c$ axis, with octahedral $\mathrm{A}(\mathrm{Al})$, tetrahedral $\mathrm{T} 2(\mathrm{Be}), \mathrm{Si}$, and two channel sites at the $\mathrm{C} 1 / 2 \mathrm{a}\left(\mathrm{H}_{2} \mathrm{O}\right.$, large alkali) and $\mathrm{C} 2 / 2 \mathrm{~b}(\mathrm{Na})$ positions; and (c) type IId, type IIs and type I $\mathrm{H}_{2} \mathrm{O}$ molecule configuration, with corresponding $\mathrm{Na}^{+}$and $\mathrm{CO}_{2}$ positions on channel sites (after Fridrichová et al., 2016).

(Charoy et al., 1996), and $\varepsilon_{\text {IIs }}=256 \mathrm{~L} / \mathrm{mol} \cdot \mathrm{cm}$, respectively (Goldman et al., 1977). Though the value for $\varepsilon_{\text {IIs }}$ is for cordierite, we expect it to equally apply for beryl to a good approximation given the similarity in water structure and index of refraction in the IR. Absorption peak intensity $A$ for each mode is approximated by the ratio of fitted peak area and line width. Using a density value of beryl calculated from XRD of $\rho=2.75 \mathrm{~g} / \mathrm{cm}^{3}$, with its variation with $\mathrm{Na}^{+}$content negligible for our case, the amount of water can be obtained as $\mathrm{H}_{2} \mathrm{O}_{\text {tot }}$ (wt.\%) $=c \times M \times 10^{-1} / \rho$ where $M$ is the molar mass of water. An ideal and maximum 1 apfu water on $\mathrm{C} 1$ corresponds to 3.24 wt.\% for an ideal beryl with $M=537.47 \mathrm{~g} / \mathrm{mol}$ (Hawthorne and Černý, 1977; Pankrath and Langer, 2002).

The resulting apfu values based on the Lambert-Beer law for $v_{1}^{\mathrm{IIs}}$ and $v_{3}^{\mathrm{I}}$ from Fig. 11a and their sum are shown in Fig. $11 \mathrm{~b}$. Type IIs water (orange) increases from 0.20 apfu in the primary phase to $0.38 \mathrm{apfu}$ in the secondary phase, correlates positively with $\mathrm{Na}^{+}$(red), and correlates negatively with $\mathrm{Fe}^{3+}$ (green) based on the co-localised LA-ICP-MS transect. Meanwhile, type I water (brown) decreases from 0.21 apfu in the primary phase to 0.12 apfu in the secondary phase. It appears that the $\sim 50 \%$ decrease of type I water in the secondary zone is more than compensated by a corresponding increase in type IIs water, with the total water content $\left(v_{1}^{\text {IIs }}+v_{3}^{\mathrm{I}}\right)$ (blue) increasing from 0.42 apfu in the primary phase to 0.50 apfu in secondary beryl.

The amount of water of 0.42 apfu determined for the primary phase by IR absorption is in good agreement with the value of 0.40 apfu derived from XRD (Table 5). The XRD result further suggests that the $\mathrm{C} 1$ site is almost half occupied with a combination of the trace amounts of alkali $\mathrm{K}^{+}, \mathrm{Cs}^{+}$and $\mathrm{Rb}^{+}$, together with water (see Table 5). The approximately equal total amount of water in primary and secondary beryl is interesting to note, with primarily a change in ratio of type I to type II water, which is controlled by the different $\mathrm{Na}^{+}$content (occupying the $\mathrm{C} 2$ site).

Corresponding spatial images are shown in Fig. 12 of type I water $(\mathrm{a}, \mathrm{d})$, type II water $(\mathrm{b}, \mathrm{e})$ and $\mathrm{CO}_{2}(\mathrm{c}, \mathrm{f})$ peak integrated
Fig. 9. Polarised Raman spectra of beryl. $(a, b) k \perp c$ axis and $E_{i n c} / /$ $c$ axis and $E_{R} / / c$ axis, (c,d) $k \perp c$ axis and $E_{\text {inc }} / / c$ axis and $E_{R} \perp c$ axis, (e,f) $k \perp c$ axis and $E_{\text {inc }} \perp c$ axis and $E_{R} \perp c$ axis. $k$ is the incident wave-vector, $E_{\text {inc }}$ and $E_{R}$ are the polarisation directions of the fundamental and Raman light, respectively. The crystallographic $z$ axis is parallel to optical $c$ axis. $A_{1 g}$ indicates the non-degenerate symmetric modes, $E_{1 \mathrm{~g}} / \mathrm{E}_{2 \mathrm{~g}}$ indicate the doubly degenerate symmetric modes. Peak assignments are listed in Table S6.
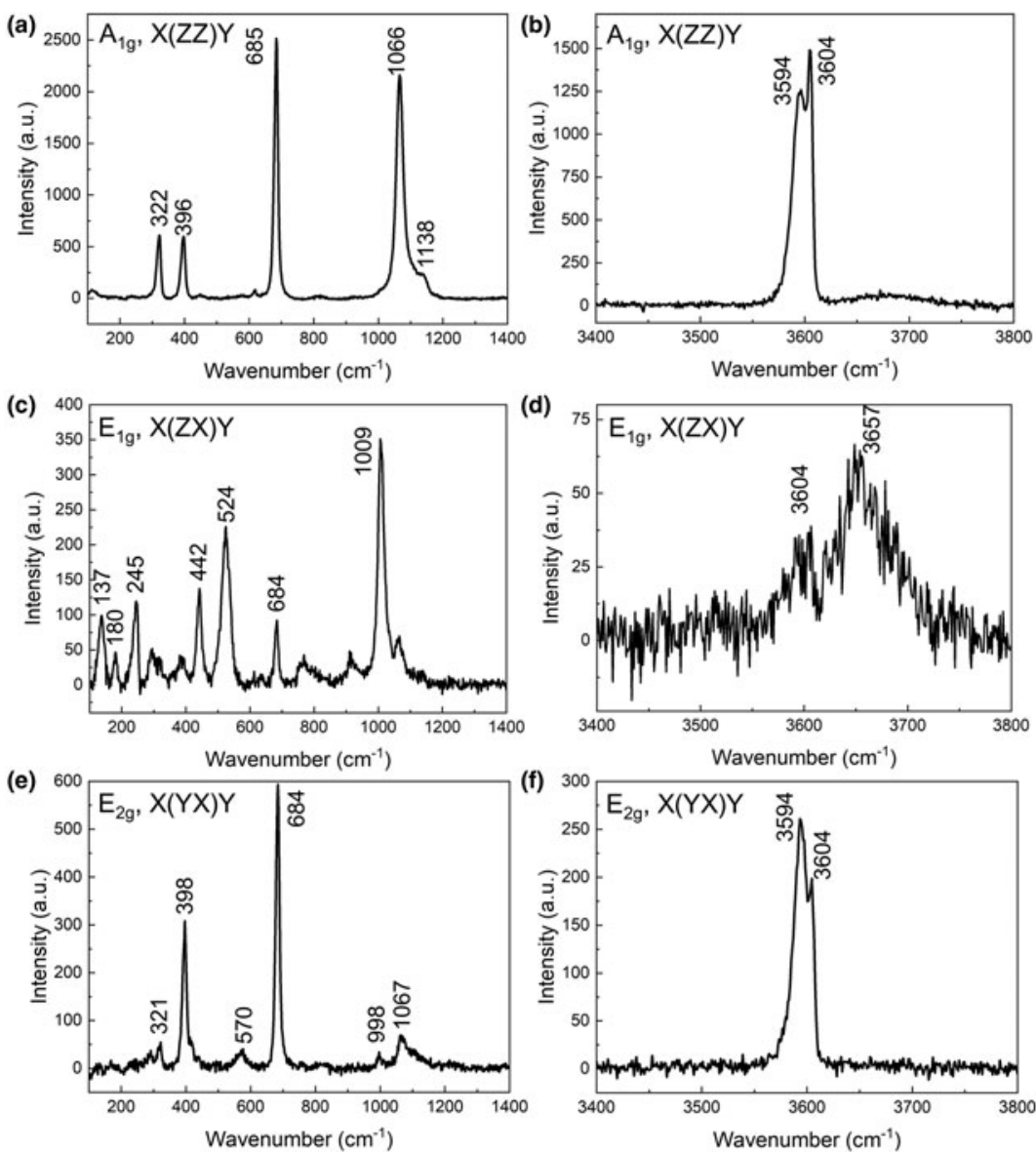

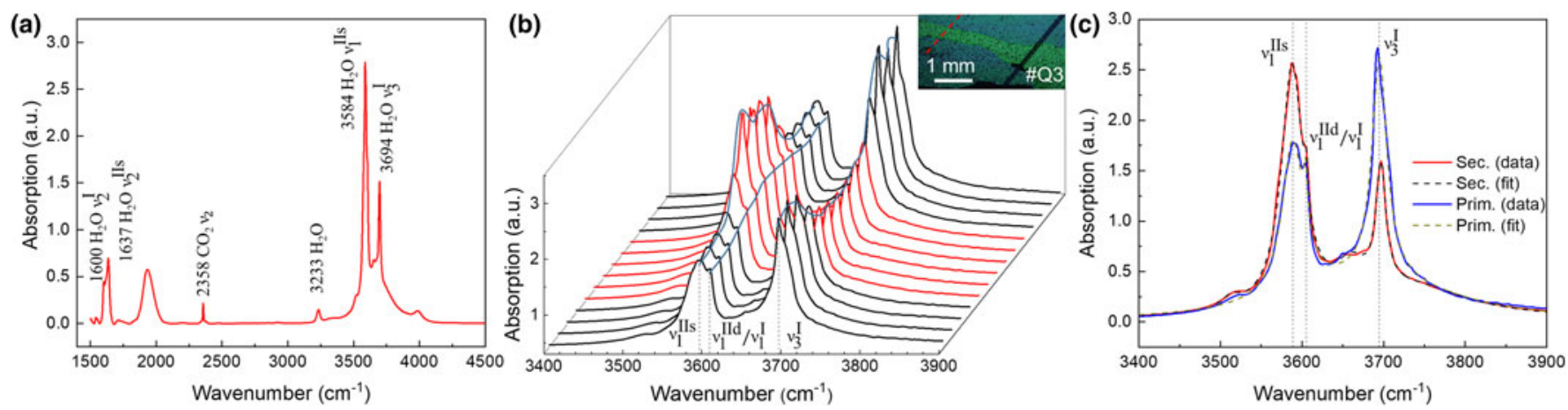

Fig. 10. IR point spectrum and micro-IR transect \#Q3-7 (for location see Fig. 3c). (a) Peak assignment with type I water (1600 and $3694 \mathrm{~cm}^{-1}$ ), type II water (1637 and $\left.3584 \mathrm{~cm}^{-1}\right)$ and $\mathrm{CO}_{2}\left(2358 \mathrm{~cm}^{-1}\right)$. (b) IR spectral transect with spectra centred on the water stretch region crossing secondary beryl zone (red) with primary beryl on either side (black) (inset: optical micrograph, with IR transect in red and LA-ICP-MS line in black). (c) Representative spectra from primary (blue) and secondary (red) zone with intense negative correlation of type I and type II water, with Lorentzian line fits (dashed) for type IIs $\left(3588 \mathrm{~cm}^{-1}\right)$, mixed type IId/I $\left(3605 \mathrm{~cm}^{-1}\right)$ and type I $\left(3694 \mathrm{~cm}^{-1}\right)$ (for details see also Fig. S5).

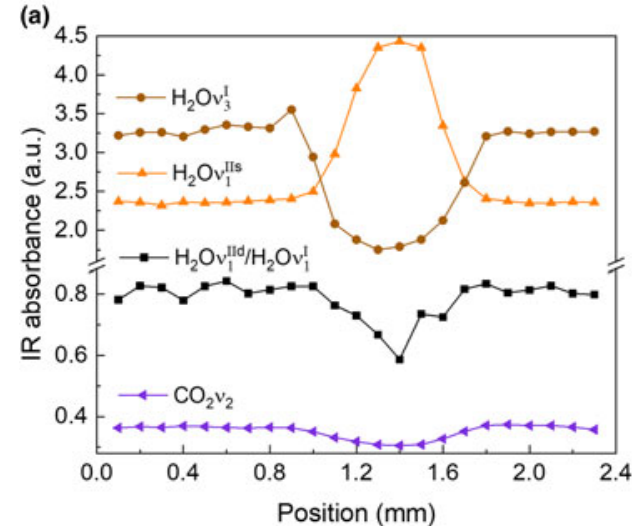

Fig. 11. IR and ICPMS transect analysis of \#Q3-7 (see Fig. 3c and Fig. 7c). (a) IR-absorbance from Lorentzian peak fits showing qualitative correlated and anti-correlated variations of $\mathrm{CO}_{2}$, type I and IIs water across primary and secondary zones. (b) Quantitative comparison of type I and type Ils (type IId negligible) water (apfu) derived from absolute IR absorption cross sections, in relation to $\mathrm{Na}$ and $\mathrm{Fe}$ content from LA-ICP-MS. values for the two crystal regions \#Q3-2 (a-c) and \#Q3-9 (d-f) as indicated in Fig. $3 c$ and acquired in proximity and an either side of the LA-ICP-MS trace (images of minor band centred at $3605 \mathrm{~cm}^{-1}$ is shown in Fig. S6 and full width at half maximum of type I in S7). Akin to the IR line trace analysis above, the same negative correlation of type I and type II water, and positive correlation of type I water with $\mathrm{CO}_{2}$ stand out.

\section{Discussion}

\section{Coupled substitution}

In the following we analyse the role of the two primary substitution vectors for the octahedrally coordinated A and tetrahedrally coordinated T2 site (Belov, 1958; Wood and Nassau, 1968; Bakakin et al., 1969; Hawthorne and Černý, 1977; Aurisicchio et al., 1988; Sherriff et al., 1991) with

$$
3^{\mathrm{T} 2} \mathrm{Be}^{2+}+\square \rightarrow(3-n) \mathrm{Be}^{2+}+n^{\mathrm{T} 2} \mathrm{Li}^{+}+n^{\mathrm{C}} \mathrm{R}^{+}
$$

and

$$
2^{\mathrm{A}} \mathrm{Al}^{3+}+\square \rightarrow(2-k) \mathrm{Al}^{3+}+g \mathrm{X}^{2+}+(k-g) \mathrm{Y}^{3+}+g^{\mathrm{C}} \mathrm{R}^{+}
$$

where $\mathrm{R}^{+}$represent alkali ions, $\mathrm{X}^{2+}$ the divalent cations, $\mathrm{Y}^{3+}$ trivalent cations, with respective coefficients $n, k$, and $g$.
Summarising the data from all EMPA and LA-ICP-MS in Fig. 13 shows the corresponding correlations for A and T2 site substitution and indicates only a weak coupling between the two substitution vectors.

Figure $13 \mathrm{a}$ shows the negative correlation of $2^{+} / 3^{+}$cations with $\mathrm{Al}^{3+}$ content based on sets of EMPA values from different samples (\#Q3, \#Q6 and \#Q7), in comparison with the theoretical behaviour based on equation 2 with slope -1 . Here we assume that all $\mathrm{Fe}^{2+} / \mathrm{Fe}^{3+}$ ions occupy the A site. The small deviation of the data from the ideal behaviour is probably due to slightly too high $\mathrm{Al}$ EMPA values, as supported by XRD suggesting $\mathrm{Al}<2$ apfu, or that $\mathrm{Fe}$ is dominated by $\mathrm{Fe}^{3+}$ (see also below). Overall, the role of A-site substitution is small, with the sum of divalent trace elements ranging from as low as $\sim 0.001$ apfu to a maximum value not exceeding $\sim 0.06$ apfu.

Figure $13 \mathrm{~b}$ shows the positive correlation of $\mathrm{Na}^{+}$with $\mathrm{Li}^{+}$ closely following the ideal behaviour with slope 1 . This shows that the substitution vector equation 1 is dominated by $\mathrm{Na}^{+}$ alone, which ranges from $91.5 \%-99.7 \%$ (apfu) of the sum of all alkali elements, and charge balancing for $\mathrm{Li}^{+}$as it substitutes for $\mathrm{Be}^{2+}$. This suggests that the remaining alkalis $\mathrm{K}^{+}, \mathrm{Rb}^{+}$and $\mathrm{Cs}^{+}$are primarily charge balancing the $\mathrm{Al}^{3+}$ substitution for divalent cations at the A site. Note the bimodal distribution with lower $\mathrm{Li}^{+}$and $\mathrm{Na}^{+}$content in the primary, and higher $\mathrm{Li}^{+}$and $\mathrm{Na}^{+}$ values in the secondary phases. Correspondingly this behaviour is to first order inversed for the other alkalis vs. $\mathrm{X}^{2+}$ cations (Fig. 13c). This suggests that in the secondary phase the role of 
Fig. 12. Micro-IR imaging on primary and secondary beryl of \#Q3-2 (a-c) and \#Q3-9 (d-f) (area indicated in Figs 3c, 7c), based on peak intensities of ( $a$ and d) type I water $\left(3694 \mathrm{~cm}^{-1}\right)$, ( $b$ and e) type IIs water $\left(3584 \mathrm{~cm}^{-1}\right)$ and $\left(\mathrm{c}\right.$ and f) $\mathrm{CO}_{2}\left(2358 \mathrm{~cm}^{-1}\right)$. Type I water is less (blue area in ( $a$ and $d)$ ), while type lls water is more in the secondary phases (red area in ( $b$ and e)). $\mathrm{CO}_{2}$ ( $c$ and $f$ ) correlates with type I water.
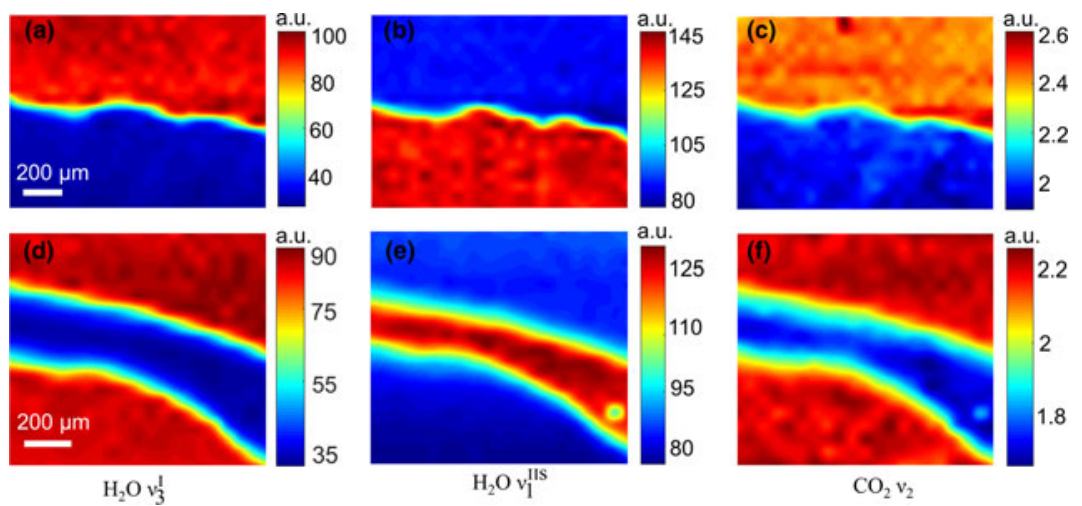

Table 5. Site-scattering refinement with site scattering and site population assignment from single crystals \#Q7, \#Q6 and \#Q3, compared to the results of EMPA and LA-ICP-MS analysis.

\begin{tabular}{|c|c|c|c|c|c|}
\hline $\begin{array}{l}\text { Crystal } \\
\text { sample }\end{array}$ & Site & $\begin{array}{l}\text { Site scattering from } \\
\text { refinement } \\
\text { (epfu) }\end{array}$ & $\begin{array}{l}\text { Site population } \\
\text { assignment } \\
\text { (apfu) }\end{array}$ & $\begin{array}{l}\text { Site population (from average chemical composition } \\
\text { from EMP and ICP-MS) } \\
\text { (apfu) }\end{array}$ & $\begin{array}{l}\text { Predicted site scattering from } \\
\text { chemical composition } \\
\text { (epfu) }\end{array}$ \\
\hline \multirow[t]{5}{*}{ \#Q7 } & $\mathrm{T} 2$ & $5.90(12)$ & 2.95(6) $\mathrm{Be}^{2+}$ & $0.289 \mathrm{Li}^{+}+2.711 \mathrm{Be}^{2+}$ & 6 \\
\hline & $A$ & 19.94(11) & $1.994(1) \mathrm{Al}^{3+}$ & $1.973 \mathrm{Al}^{3+}+0.022 \mathrm{Mg}^{2+}+0.008 \mathrm{Fe}^{3+}$ & 20.13 \\
\hline & $\mathrm{T} 1$ & $59.64(2)$ & $5.964(2) \mathrm{Si}^{4+}$ & $5.998 \mathrm{Si}^{4+}$ & 59.98 \\
\hline & $\mathrm{C} 2$ & $3.096(2)$ & $0.3096(2) \mathrm{Na}^{+}$ & $0.293 \mathrm{Na}^{+}$ & 2.93 \\
\hline & $\mathrm{C} 1$ & $4.56(2)$ & $0.456(2) \mathrm{H}_{2} \mathrm{O}$ & $0.003 \mathrm{~K}^{+}+0.015 \mathrm{Cs}^{+}+0.368 \mathrm{H}_{2} \mathrm{O}^{\star}$ & 4.56 \\
\hline \multirow[t]{5}{*}{ \#Q6 } & $\mathrm{T} 2$ & $5.81(12)$ & $2.905(6) \mathrm{Be}^{2+}$ & $0.284 \mathrm{Li}^{+}+2.716 \mathrm{Be}^{2+}$ & 6 \\
\hline & $A$ & $19.86(13)$ & $1.986(1) \mathrm{Al}^{3+}$ & $2.020 \mathrm{Al}^{3+}+0.010 \mathrm{Mg}^{2+}+0.009 \mathrm{Fe}^{3+}$ & 20.51 \\
\hline & $\mathrm{T} 1$ & $60.00(4)$ & $6.0(4) \mathrm{Si}^{4+}$ & $5.969 \mathrm{Si}^{4+}$ & 59.69 \\
\hline & $\mathrm{C} 2$ & $3.2244(2)$ & $0.32244(2) \mathrm{Na}^{+}$ & $0.358 \mathrm{Na}^{+}$ & 3.58 \\
\hline & $\mathrm{C} 1$ & $4.86(2)$ & $0.486(2) \mathrm{H}_{2} \mathrm{O}$ & $0.004 \mathrm{Cs}^{+}+0.464 \mathrm{H}_{2} \mathrm{O}^{\star}$ & 4.86 \\
\hline \multirow[t]{5}{*}{ \#Q3 } & $\mathrm{T} 2$ & $5.83(12)$ & $2.915(6) \mathrm{Be}^{2+}$ & $0.249 \mathrm{Li}^{+}+2.751 \mathrm{Be}^{2+}$ & 6 \\
\hline & $A$ & $19.89(12)$ & $1.989(1) \mathrm{Al}^{3+}$ & $2.008 \mathrm{Al}^{3+}+0.003 \mathrm{Mg}^{2+}+0.009 \mathrm{Fe}^{3+}$ & 20.32 \\
\hline & $\mathrm{T} 1$ & $59.88(2)$ & $5.988(2) \mathrm{Si}^{4+}$ & $5.982 \mathrm{Si}^{4+}$ & 59.82 \\
\hline & $\mathrm{C} 2$ & $2.928(2)$ & $0.2928(2) \mathrm{Na}^{+}$ & $0.252 \mathrm{Na}^{+}$ & 2.52 \\
\hline & $\mathrm{C} 1$ & $4.56(2)$ & $0.456(2) \mathrm{H}_{2} \mathrm{O}$ & $0.003 \mathrm{~K}^{+}+0.009 \mathrm{Cs}^{+}+0.401 \mathrm{H}_{2} \mathrm{O}^{*}$ & 4.56 \\
\hline
\end{tabular}

epfu - electrons per formula unit

$\mathrm{H}_{2} \mathrm{O}^{*}$ is estimated by site scattering (epfu) except sum of $\mathrm{K}^{+}, \mathrm{Cs}^{+}$and $\mathrm{Rb}^{+}$.

the T2 substitution vector (equation 1 ) increases, whereas the A substitution vector (equation 2) diminishes. The deviations of certain data groups (green and red) in Fig. 13c with negative correlation in Fig. 13b suggests a weak coupling between the two substitution vectors through the alkali $\mathrm{R}^{+}$mixing.

Combining both substitutions of equations 1 and 2 in Fig. 13d shows the sum of the vector $\mathrm{Li}^{+}$for $\mathrm{Be}^{2+}$ at the $\mathrm{T} 2$ site, and the sum of all divalent cations to replace for $\mathrm{Al}^{3+}$ at the $\mathrm{A}$ site. The good agreement with the theoretical slope of 1 for all data, in contrast to (b) or (c) suggests that all iron at the A site is trivalent, i.e. not necessitating charge balancing with alkalis (Fe with other divalent cations vs. alkali elements see Fig. S8).

The combined results can then be expressed by the empirical formula:

$$
\begin{aligned}
& { }^{T 2}\left(\mathrm{Be}_{2.62-2.75} \mathrm{Li}_{0.25-0.38}\right)_{\Sigma 3.00} \\
& { }^{A}\left[\mathrm{Al}_{1.94-2.00}\left(\mathrm{Mg}, \mathrm{Fe}^{3+}, \mathrm{Ca}, \mathrm{Mn}, \mathrm{Ti}\right)_{<0.06}\right]_{\Sigma 2.00} \\
& { }^{T 1} \mathrm{Si}_{6} \mathrm{O}_{18}{ }^{C 2}\left[( \mathrm { Na } _ { 0 . 2 5 - 0 . 3 6 } ( \mathrm { K } , \mathrm { Rb } , \mathrm { Cs } ) _ { < 0 . 0 2 } ] \cdot { } ^ { C 1 } \left(\mathrm{H}_{2} \mathrm{O}_{0.4-0.5}\left(\mathrm{CO}_{2}\right)_{<0.01}\right.\right.
\end{aligned}
$$

In accordance with the International Mineralogical Association Commission on New Minerals, Nomenclature and
Classification guidance (Bosi et al., 2019), this formula leads to the end-member composition ${ }^{\mathrm{T} 2} \mathrm{Be}_{3}{ }^{\mathrm{A}} \mathrm{Al}_{2}{ }^{\mathrm{T} 1} \mathrm{Si}_{6} \mathrm{O}_{18}$ (beryl). In summary, the sample studied can be classified as ( $\mathrm{Li}, \mathrm{Na}$-rich) beryl.

\section{Crystal structure}

The Si value close to ideal 6 apfu by EMPA indicates a negligible $\mathrm{Si}-\mathrm{Al}$ substitution. The tetrahedral volumes are 2.133, 2.133 and $2.136 \AA^{3}$ for \#Q7, \#Q6 and \#Q3 (Table 4), respectively, values typical for pure $\mathrm{Si}$ tetrahedral sites.

The distinct coordination of water with $\mathrm{Na}^{+}$features a shorter bond length of $\mathrm{H}-\mathrm{O} 1$ for type IIs compared to type IId (Fukuda and Shinoda, 2008, 2011). This results in a correspondingly larger bond strength giving rise to a higher frequency of the IR bending mode. Our type IIs bending mode value of $1637 \mathrm{~cm}^{-1}$ agrees with the range of theoretical peak positions of $1637-1639 \mathrm{~cm}^{-1}$ for type IIs water rather than $1624-1627 \mathrm{~cm}^{-1}$ for type IId water (Fridrichová et al., 2016).

Theoretical $\mathrm{Na}-\mathrm{O}$ bond lengths of type IIs and IId are $2.227 \AA$ and $2.483 \AA$, and $\mathrm{Na}-\mathrm{O} 1$ bond lengths of IIs and IId are $2.558 \AA$ and $2.540 \AA$, respectively (Fridrichová et al., 2016). The IIs values are in good agreement with our measured values of the average $\mathrm{Na}-\mathrm{O}$ and $\mathrm{Na}-\mathrm{O} 1$ band lengths of $2.305 \AA$ and $2.556 \AA$, respectively. This indicates the $\mathrm{Na}$ bound water is primarily type IIs. 


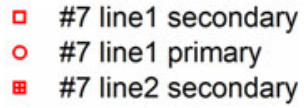

(a)
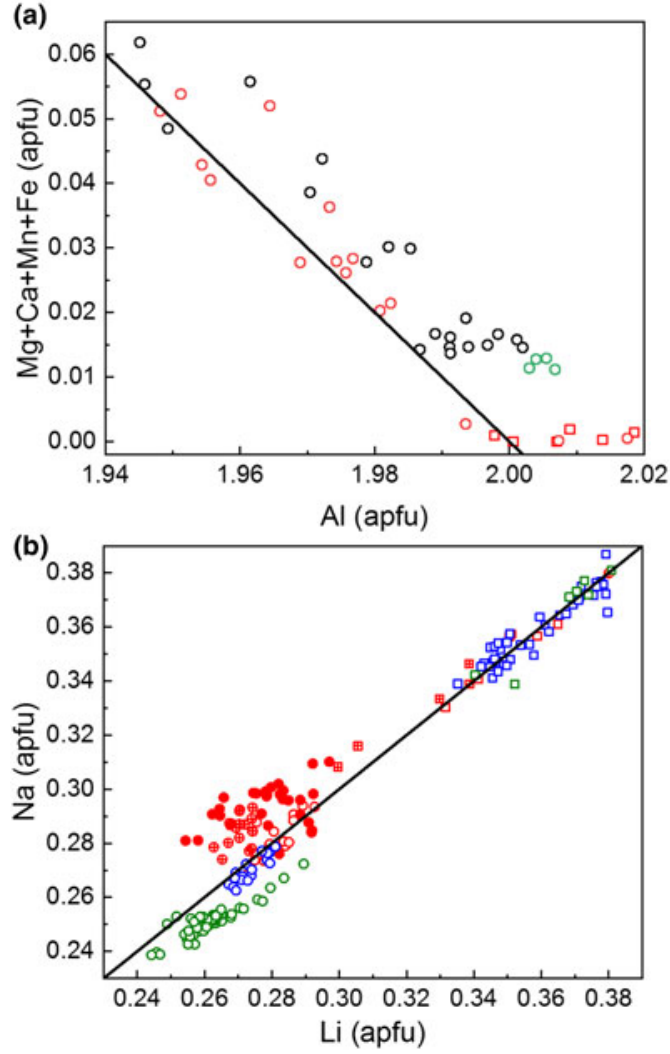

- \#6 line primary

\#3 line secondary

- \#3 line primary
○ zoning

(c)

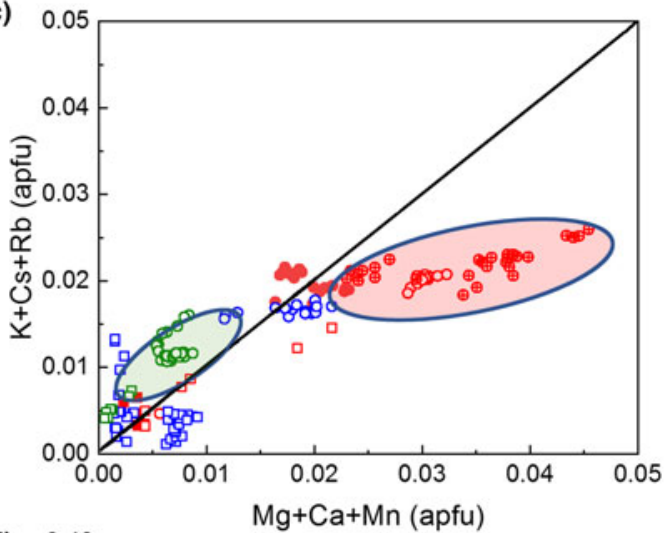

(d)

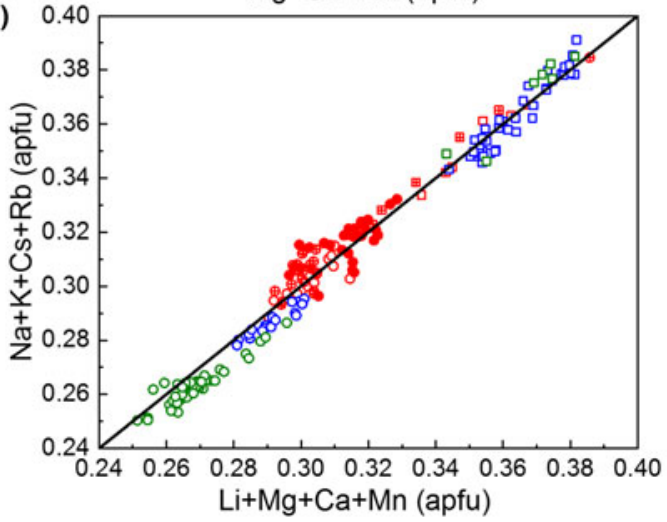

Fig. 13. Correlations and trends in major-element variations. (a) Linear correlation between A-site Al and corresponding $X^{2+}$ (divalent ions at the $A$ site) substituents. (b) Correlation between $\mathrm{T}_{2} \mathrm{Li}^{+}$substitution for $\mathrm{Be}^{2+}$ with $\mathrm{Na}^{+}$charge balancing on the $\mathrm{C} 2$ site. (c) $\mathrm{R}^{+}-\mathrm{Na}^{+}$vs. $\mathrm{X}^{2+}$ with inversely correlated deviations of some data groups compared to (b), indicating weak coupling between the two substitution vectors. (d) Combined A and T2 substitution expressed as $\mathrm{R}^{+}$(monovalent alkali ions in channel) vs. $\mathrm{Li}^{+}+\mathrm{X}^{2+}-\mathrm{Fe}^{3+}$ with linear correlation. (a) Based on microprobe data, (b-d) LA-ICP-MS data. Black lines represent the ideal substitution or charge balance relationship, $\mathrm{Al}^{3+}+\mathrm{X}^{2+}=2(\mathrm{a}) ; \mathrm{Li}^{+}=\mathrm{Na}^{+}(\mathrm{b}) ; \mathrm{R}^{+}-\mathrm{Na}^{+}=\mathrm{X}^{2+}(\mathrm{c})$ and $\mathrm{R}^{+}=\mathrm{Li}^{+}+\mathrm{X}^{2+}-\mathrm{Fe}^{3+}(\mathrm{d})$.

\section{Water content}

The water estimates based on the absolute IR absorbed intensity, consistent with the results from XRD informed by LA-ICP-MS, indicate that the water occupancy ranges from 0.4 apfu to 0.5 apfu in \#Q7, which is close to half of the maximum water occupation with an approximate stoichiometry of $\mathrm{Be}_{3} \mathrm{Al}_{2} \mathrm{Si}_{6} \mathrm{O}_{18}$. $0.5 \mathrm{H}_{2} \mathrm{O}$. Similarly, from XRD, the water occupation is close to 0.5 apfu for \#Q6 (0.46), yet slightly low for \#Q7 (0.37) and \#Q3 (0.40). The $\mathrm{Na}^{+}$content $(\mathrm{C} 2 / 2 \mathrm{~b}$ site) controls the dipole orientation and types of water on the channel site in the centre of the Si rings $\left(\mathrm{Cl} / 2\right.$ a site) with type II water correlated with $\mathrm{Na}^{+}$content as expected.

Few other investigations have yet addressed the water content in Xuebaoding beryl. Only Guo et al. (2000b) and Lin et al. (2000) have estimated the water content using a wet chemical method and obtained values of $1.97 \mathrm{wt} . \%$ to $3.56 \mathrm{wt} . \%$ corresponding to apfu values ranging from 0.61 to 1.13 , with the later value exceeding the maximum possible value of 1 apfu.

From other localities, water content in beryl was determined by wet-chemical analyses (Charoy et al., 1996; Guo et al., 2000b; Lin et al., 2000), thermogravimetric analyses (Artioli et al., 1993; Pankrath and Langer, 2002; Gatta et al., 2006; Fridrichová et al., 2016), or based on the empirical equation
$\mathrm{H}_{2} \mathrm{O}$ (in wt.\%) $=\left[0.84958 \times \mathrm{Na}_{2} \mathrm{O}\right.$ (in wt.\%) $]+0.8373$ (Giuliani et al., 1997; Groat et al., 2008; Fridrichová et al., 2016), with values ranging from $<1 \mathrm{wt} . \%$ to $>3 \mathrm{wt} . \%$. However, these methods configure sensitivity to the type of water, or may overestimate including fluid inclusions or water on grain boundaries. This highlights the value of quantitative micro-IR spectroscopy with spatial resolution and site specificity.

\section{Comparison with previous Xuebaoding beryl studies}

The results of EMPA and LA-ICP-MS are in agreement with some but not all prior studies of beryl from Xuebaoding which are summarised in Table S1 and S7. In general good agreement is found with Guo et al. (2000b), Qi et al. (2001b) and Zhou et al. (2002). Yet results from Liu et al. (2001b), republished in Liu et al. (2005) are inconsistent with ours, reporting high $\mathrm{SiO}_{2}$ (66.04-67.25 wt.\%) and low $\mathrm{Na}_{2} \mathrm{O}$ (0.42-0.83 wt.\%). A bulk wet-chemical analysis (Liu et al., 2001a; Qi et al., 2001c) republished in Liu et al. (2005) and again in Liu et al. (2007) is in general agreement with our results, except for their third set of data with low $\mathrm{Na}_{2} \mathrm{O}\left(0.27\right.$ wt.\%) and high $\mathrm{FeO}^{\mathrm{T}}$ (0.76 wt.\%) (bolded data in Table S7). A later analysis by the same authors using LA-ICP-MS and XRF (Liu et al., 2012) is again inconsistent 
with implausibly high $\mathrm{Li}^{+}\left(\mathrm{Li}_{2} \mathrm{O}\right.$ 2.60-3.04 wt.\%) that cannot be charge balanced by the other alkali as quantified. A single wet-chemical analysis (Lin et al., 2000) reports exceptionally high $\mathrm{Fe}(0.67$ wt.\%) and $\mathrm{Ca}(0.88$ wt.\%).

Our XRD unit-cell parameter derived data are in good agreement with an earlier analysis of Guo et al. (2000a) with $a=9.209$ (2) $\AA$ and $c=9.2221(9) \AA$ with $c / a=1.0001$. However, our results are in disagreement with Liu et al. (2007) that reports implausibly short $a$ and $c$ values based on small number of reflections and poor $R$ value. Instead, our results are in better agreement with earlier (Liu et al., 2005) and later work (Liu et al., 2012) by the same authors.

\section{Comparison with beryl of similar structure and chemistry from other localities}

The Xuebaoding beryl is overall characterised by a simple chemistry with minor octahedral (A) site substitution with $\mathrm{Fe}^{3+}$ and $\mathrm{Mg}^{2+}$ and negligible $\mathrm{Ti}^{4+}, \mathrm{Zn}^{2+}$ or $\mathrm{Ca}^{2+}$ with charge balance through $\mathrm{Cs}^{+}$and minor $\mathrm{Rb}^{+}$and $\mathrm{K}^{+}$. $\mathrm{Fe}$ as $\mathrm{Fe}^{3+}$ is suggested to substitute for $\mathrm{Al}^{3+}$ on the A site (Aurisicchio et al., 1988; Neiva and Neiva, 2005; Groat et al., 2008, 2010). The low $\mathrm{Fe}^{3+}$ content is consistent with only a light colour trend towards blue (aquamarine) (Mihalynuk and Lett, 2003; Fridrichová et al., 2015; Lum et al., 2016). Appreciable $\mathrm{Li}^{+}$substitution for $\mathrm{Be}^{2+}$ on the tetrahedral (T2) site with $\mathrm{Li}^{+}$up to 0.38 is on the high end compared to other localities worldwide (Aurisicchio et al., 1988) and charge balanced by $\mathrm{Na}^{+}$incorporation on the channel site. This classifies the Xuebaoding beryl as '(Na, Li) beryl' (Černý, 1975) as typically associated with Li-rich pegmatites, and of the crystallographic 'tetrahedral' variety, i.e. the dominance of the T2 site $\mathrm{Li}$ substitution as opposed to A-site substitution (Aurisicchio et al., 1988).

Compared to beryl from other localities worldwide, the chemical composition and structure of beryl from Xuebaoding do not stand out in any particular way (Hawthorne and Černý, 1977; Aurisicchio et al., 1988, 1994; Sherriff et al., 1991; Artioli et al., 1993; Černý et al., 2003; Groat et al., 2008; Lum et al., 2016). The $\mathrm{Si}^{4+}$ content of most beryl is close to $6 . \mathrm{Al}^{3+}$ apfu values generally range from as low as 1.2 in few cases, to 2 , with the majority of data above $1.5 \mathrm{apfu}$, compared to Xuebaoding beryl with $\mathrm{Al}^{3+}$ close to 2 apfu. $\mathrm{Be}^{2+}$ ranges from 2.5 to 3.0 apfu (Hawthorne and Černý, 1977; Aurisicchio et al., 1988, 1994; Sherriff et al., 1991; Artioli et al., 1993; Černý et al., 2003), similar to Xuebaoding beryl varying between 2.62 and 2.75 apfu. $\mathrm{Be}^{2+}$ substitution for $\mathrm{Li}^{+}$and correlated with $\mathrm{Na}^{+}$is observed frequently with $\mathrm{Li}^{+}$ranging from 0 to 0.5 apfu (with Xuebaoding $\mathrm{Li}^{+}$of 0.25 to 0.4 apfu in the middle of that range).

With site substitution controlling the unit-cell parameters (Pankrath and Langer, 2002), the values for the $a$ axis range from 9.202 to $9.228 \AA$ and the $c$ axis from 9.185 to $9.240 \AA$ (Hawthorne and Černý, 1977; Aurisicchio et al., 1988; Sherriff et al., 1991; Artioli et al., 1993; Černý et al., 2003). Corresponding values for Xuebaoding beryl fall within the middle of that range. Notably similar in composition and unit-cell parameter to Xuebaoding beryl \#Q7, is beryl from the Mount Bity region, Madagascar (pale pink sample \#18, Aurisicchio et al., 1988), with $\mathrm{Si}^{4+}=6$ and $\mathrm{Al}^{3+}=2 ; \mathrm{Li}^{+}=0.27$ substituting $\mathrm{Be}^{2+}$ at the T2 site; and $\mathrm{Na}^{+}=0.18$ and $\mathrm{Cs}^{+}=0.02$ occupying the channel to balance the charge - resulting in $a=9.215 \AA$ and $c=9.218 \AA$, closely resembling the Xuebaoding beryl values of $a=9.2161(2) \AA$ and $c=9.2178(2) \AA$. The beryl from Pala, California, USA (pale pink sample \#28, Aurisicchio et al., 1988) with $a=9.213 \AA$ and $c=9.212 \AA$, and with similar composition of $\mathrm{Si}^{4+}=5.996$, $\mathrm{Al}^{3+}=2.004$, but lower $\mathrm{Li}^{+}=0.17$ and $\mathrm{Na}^{+}=0.14$ matches Xuebaoding sample \#Q7 closely.

\section{Comparison with tabular beryl worldwide}

A particular feature of Xuebaoding beryl is the tabular habit. Similar tabular habits are observed in 'morganite' (pink beryl) (Cook, 2011) from San Diego County, California, USA, yet crystals exhibit dominance of A-site substitution $\left(\mathrm{Mn}^{2+}\right)$ with charge balanced by $\mathrm{Cs}^{+}$(on C1) and low water content. Clear beryl (goshinite) from lithium-rich microcline-albite pegmatites from Minas Gerais, Brazil (Cook, 2011) sometimes occur as tabular crystals, with high $\mathrm{Li}^{+}$and $\mathrm{Na}^{+}$content and are water rich (Fukuda and Shinoda, 2011). Similarly, tabular beryl from the Bikita rare-element granitic pegmatite, Zimbabwe, exhibit high $\mathrm{Li}^{+}$content and T2-site substitution (Černý et al., 2003) with alkali charge balancing, and only minor A-site substitution. The beryl-group member pezzottaite with maximum lithium substitution on T2 (ideally $\mathrm{Cs}\left(\mathrm{Be}_{2} \mathrm{Li}\right) \mathrm{Al}_{2} \mathrm{Si}_{6} \mathrm{O}_{18}$, Yakubovich et al., 2009) also exhibits a tabular habit. The crystal chemistry of the Xuebaoding beryl, while not deterministic with regards to the crystal habit, may still give some insight into the evolution of the ore-forming fluids (Černý, 2002; Černý et al., 2003; Uher et al., 2010; Sardi and Heimann, 2014). The alkali and ferromagnesian content can reflect the evolution and composition of the host fluid (Černý, 1975).

\section{Summary and implications}

Overall, the Xuebaoding beryl exhibit very similar tabular habit throughout the deposit, only rarely columnar, or etched. This suggests generally similar and stable conditions during the crystallisation of the veins. The low $\mathrm{Fe}^{3+}$ and $\mathrm{Mg}^{2+}$ content is consistent with the low degree of $\mathrm{Fe}^{3+}$ mineralisation in general (minor pyrite). The secondary phases in crystal sections or metasomatic replacement with decrease in $\mathrm{Fe}^{3+}$ and $\mathrm{Mg}^{2+}$, yet increase in $\mathrm{Na}^{+}$, indicate a further evolution and fractionation of the fluid in its late stage. This would support the hypothesis of early crystallisation of aquamarine with goshenite being late. These observations relate to the suggestion that goshenite is associated with highly evolved fluids, e.g. in pegmatites (Černý et al., 2003; Neiva and Neiva, 2005; Wang et al., 2009) and with the limited $\mathrm{Fe}^{3+}$ and A-site substitution not being of magmatic origin. These results are further consistent with the understanding that the Xuebaoding $\mathrm{W}-\mathrm{Sn}-\mathrm{Be}-\mathrm{F}-\mathrm{P}$ mineralisation is primarily hydrothermal in origin and derived from a highly evolved fluid emerging from the Pankou and Pukouling albite leucogranites that are highly fractionated, alkali, peraluminous, Li-F-enriched (Zhu et al., 2020) giving rise to the beryl, cassiterite, scheelite, fluorite and apatite mineral assemblage.

The tabular habit is therefore unlikely to be related to chemical composition and alkali content. However, the factors that control crystal habit in this and other localities remain unknown. More plausible than a chemical effect is the role of pressure and temperature, giving rise to anisotropy in lattice compressibility and thermal expansion. That may control, not only the size of lattice sites affecting substitution, but also the free energy of and preferential growth along particular crystallographic directions. Understanding the relationship of crystal habit to chemical, pressure and temperature conditions of the source fluid would be a subject of considerable general importance. 
Acknowledgements. PW and MBR thank Chen Meng, Chen Yangang, Yin Xianyong, Wu Shunjin and Zeng Taiyun from the local community enabling field work and providing sample material. We thank Zhong Qian, Lai Meng, and $\mathrm{Xu}$ Xing for help with the micro-IR measurement. We acknowledge Mark Jacobsen, Bert Ottens, Alfred Schreilechner and Philip Persson for valuable discussions. We are indebted to the reviewers Junichi Fukuda and Gioacchino Tempesta for valuable input. In addition, we thank miners, mountain guides and area residents for their hospitality, dedication and invaluable support.

Supplementary material. To view supplementary material for this article, please visit https://doi.org/10.1180/mgm.2021.13

\section{References}

Adamo I., Pavese A., Prosperi L., Diella V., Ajò D., Gatta G.D. and Smith C.P. (2008) Aquamarine, maxixe-type beryl, and hydrothermal synthetic blue beryl: analysis and identification. Gems \& Gemology, 44, 214-226.

Aines R.D. and Rossman G.R. (1984) Water in minerals? A peak in the infrared. Journal of Geophysical Research: Solid Earth, 89, 4059-4071.

Armstrong J.T. (1988) Quantitative analysis of silicates and oxide minerals: comparison of Monte-Carlo, ZAF and Phi-Rho-Z procedures. Pp. 239246 in: Proceedings of Microbeam Analysis Society (D.E. Newbury, editor). San Francisco Press, San Francisco.

Artioli G., Rinaldi R., Stahl K. and Zanazzi P.F. (1993) Structure refinements of beryl by single-crystal neutron and X-ray diffraction. American Mineralogist, 78, 762-768.

Aurisicchio C., Fioravanti G., Grubessi O. and Zanazzi P. (1988) Reappraisal of the crystal chemistry of beryl. American Mineralogist, 73, 826-837.

Aurisicchio C., Grubessi O. and Zecchini P. (1994) Infrared spectroscopy and crystal chemistry of the beryl group. The Canadian Mineralogist, 32, 55-68.

Azavant P. and Lichanot A. (1993) X-ray scattering factors of oxygen and sulfur ions: an ab initio Hartree-Fock calculation. Acta Crystallographica, A49, 91-97.

Bakakin V.V., Rylov G.M. and Belov N.V. (1969) Crystal structure of a lithiumbearing beryl. Doklady Akademii Nauk SSSR, 188, 659-662.

Belov N.V. (1958) Essays on structural mineralogy IX. Mineralogicheskiy Sbornik L'vovskogo Obshchestva, 12, 15-42 [in Russian].

Bosi F., Hatert F., Hålenius U., Pasero M., Miyawaki R. and Mills S.J. (2019) On the application of the IMA-CNMNC dominant-valency rule to complex mineral compositions. Mineralogical Magazine, 83, 627-632.

Cao Z., Zheng J., Li Y., Ren J., Xu S., Wang R., Shoji T., Kaneda H. and Kabayashi S. (2002) Geologic and geochemical features of the volatile-rich ore fluid and its tracing and dating in the Xuebaoding Beryl-Scheelite Vein Deposit, China. Science in China, Series D: Earth Sciences, 45, 719-729.

Cao Z., Jianbin Z., An W. and Youguo L. (2004) Geochemistry of Xuebaoding alkali granite and its ore-controlling effect. Journal of Ocean University of Qingdao, 34, 874-880.

Černý P. (1975) Alkali variations in pegmatitic beryls and their petrogenetic implications. Neues Jahrbuch für Mineralogie - Abhandlungen, 123, 198-212.

Černý P. (2002) Mineralogy of beryllium in granitic pegmatites. Pp. 405-444 in: Beryllium: Mineralogy, Petrology, and Geochemistry (E.S. Grew, editor). Reviews in Mineralogy and Geochemistry, 50. Mineralogical Society of America and the Geochemical Society, Chantilly, Virginia, USA.

Černý P., Anderson A.J., Tomascak P.B. and Chapman R. (2003) Geochemical and morphological features of beryl from the Bikita granitic pegmatite, Zimbabwe. The Canadian Mineralogist, 41, 1003-1011.

Chantler C.T., Olsen K., Dragoset R.A., Chang J., Kishore A.R., Kotochigova S.A. and Zucker D.S. (2005) X-Ray Form Factor, Attenuation, and Scattering Tables (Version 2.1). National Institute of Standards and Technology, Gaithersburg, MD, USA. [Online at http://physics.nist.gov/ ffast, retrieved 2 August 2020].

Charoy B., De Donato P., Barres O. and Pinto-Coelho C. (1996) Channel occupancy in an alkali-poor beryl from Serra Branca (Goias, Brazil): Spectroscopic characterization. American Mineralogist, 81, 395-403.

Chen Z., Wan S., Lu X. and Wang W. (2002) Study on fluid inclusions in beryl from Pingwu, Sichuan province. Geological Science and Technology Information, 21, 65-73.
Cook R.B. (2011) Connoisseur's choice: Beryl, variety morganite San Diego County, California. Rocks and Minerals, 86, 50-57.

Cromer D.T. and Mann J.B. (1968) X-ray scattering factors computed from numerical Hartree-Fock wave functions. Acta Crystallographica, A24, 321-324.

Della Ventura G., Radica F., Bellatreccia F., Freda C. and Cestelli Guidi M. (2015) Speciation and diffusion profiles of $\mathrm{H}_{2} \mathrm{O}$ in water-poor beryl: comparison with cordierite. Physics and Chemistry of Minerals, 42, 735-745.

Donovan J.J., Singer J.W. and Armstrong J.T. (2016) A new EPMA method for fast trace element analysis in simple matrices. American Mineralogist, 101, 1839-1853.

Folinsbee R.E. (1941) Optic properties of cordierite in relation to alkalies in the cordierite-beryl structure. American Mineralogist, 26, 485-500.

Fridrichová J., Bačík P., Rusinová P., Antal P., Škoda R., Bizovská V. and Miglierini M. (2015) Optical and crystal-chemical changes in aquamarines and yellow beryls from Thanh Hoa province, Vietnam induced by heat treatment. Physics and Chemistry of Minerals, 42, 287-302.

Fridrichová J., Bačík P., Bizovská V., Libowitzky E., Škoda R., Uher P., Ozdín D. and Števko M. (2016) Spectroscopic and bond-topological investigation of interstitial volatiles in beryl from Slovakia. Physics and Chemistry of Minerals, 43, 419-437.

Fukuda J. and Shinoda K. (2008) Coordination of water molecules with $\mathrm{Na}^{+}$ cations in a beryl channel as determined by polarized IR spectroscopy. Physics and Chemistry of Minerals, 35, 347-357.

Fukuda J. and Shinoda K. (2011) Water molecules in beryl and cordierite: High-temperature vibrational behavior, dehydration, and coordination to cations. Physics and Chemistry of Minerals, 38, 469-481.

Fukuda J., Shinoda K., Nakashima S., Miyoshi N. and Aikawa N. (2009) Polarized infrared spectroscopic study of diffusion of water molecules along structure channels in beryl. American Mineralogist, 94, 981-985.

Gatta G.D., Nestola F., Bromiley G.D. and Mattauch S. (2006) The real topological configuration of the extra-framework content in alkali-poor beryl: A multi-methodological study. American Mineralogist, 91, 29-34.

Ginzburg A.I. (1955) On the question of the composition of beryl. Trudy Mineralogicheskogo Muzeya, Akademiya Nauk, 7, 56.

Giuliani G., France-Lanord C., Zimmermann J.L., Cheilletz A., Arboleda C., Charoy B., Coget P., Fontan F. and Giard D. (1997) Fluid composition, $\delta \mathrm{D}$ of channel $\mathrm{H}_{2} \mathrm{O}$, and $\delta^{18} \mathrm{O}$ of lattice oxygen in beryls: Genetic implications for brazilian, colombian, and afghanistani emerald deposits. International Geology Review, 39, 400-424.

Goldman D.S., Rossman G.R. and Dollase W.A. (1977) Channel constituents in cordierite. American Mineralogist, 62, 1144-1157.

Groat L.A., Giuliani G., Marshall D.D. and Turner D. (2008) Emerald deposits and occurrences: A review. Ore Geology Reviews, 34, 87-112.

Groat L.A., Rossman G.R., Dyar M.D., Turner D., Piccoli P.M.B., Schultz A.J. and Ottolini L. (2010) Crystal chemistry of dark blue aquamarine from the true blue showing, Yukon territory, Canada. The Canadian Mineralogist, 48, 597-613.

Guo Y., Wang R., Xu S., Fontan F., Luo Y. and Cao Z. (2000a) A study of the structure of a rare tabular crystal of beryl. Geological Review, 46, 312-317.

Guo Y., Wang R. and Xu S. (2000b) Vibrational spectra of beryl from Xuebaoding, Pingwu County, Sichuan Province. Geological Journal of China Universities, 2, 201-204.

Hagemann H., Lucken A., Bill H., Gysler-Sanz J. and Stalder H. (1990) Polarized Raman spectra of beryl and bazzite. Physics and Chemistry of Minerals, 17, 395-401.

Hawthorne F.C. and Černý P. (1977) The alkali-metal positions in Cs-Li beryl. The Canadian Mineralogist, 15, 414-421.

Jiang S., Zhou Y., Guo C., Cao Y. and Xu H. (2007) Fluid inclusions of the Pingwu W-Sn-Be deposit in Sichuan. Geological Review, 53, 407-412.

Kim C.C., Bell M.I. and McKeown D.A. (1995) Vibrational analysis of beryl $\left(\mathrm{Be}_{3} \mathrm{Al}_{2} \mathrm{Si}_{6} \mathrm{O}_{18}\right)$ and its constituent ring $\left(\mathrm{Si}_{6} \mathrm{O}_{18}\right)$. Physica B: Physics of Condensed Matter, 205, 193-208.

Kirby E. and Ouimet W. (2011) Tectonic geomorphology along the eastern margin of Tibet: insights into the pattern and processes of active deformation adjacent to the Sichuan Basin. Pp. 165-188 in: Growth and Collapse of the Tibetan Plateau (R. Gloaguen and L. Ratschbacher, editors). Geological Society, London, Special Publications, 353. 
Kolesov B.A. and Geiger C.A. (2000) The orientation and vibrational states of $\mathrm{H}_{2} \mathrm{O}$ in synthetic alkali-free beryl. Physics and Chemistry of Minerals, 27, $557-564$.

Li J., Liu B., Wang D. and Fu X. (2007) Metallogenic epoch of Xubaoding W$\mathrm{Sn}-\mathrm{Be}$ deposit in northwest Sichuan and its tectonic tracing significance. Mineral Deposits, 26, 557-562.

Lin J., Cao Z., Liu J., Li Y., Zhang Y. and Ying S. (2000) Mineral spectroscopic studies of beryls from Xuebaoding, Sichuan. Acta Petrrologica et Mineralogica, 19, 369-375.

Liu Y., He M., Zhang D., Yu X. and Pan Z. (2001a) Gemmology of Beryl from Pingwu, Sichuan Province. Journal of Gems \& Gemmology, 3, 31-34.

Liu Y., Zhang B. and Yu X. (2001b) The mineralogical characteristics and its application prospect of beryl in Pingwu, Sichuan. Geology and Prospecting, $37,55-57$.

Liu Y., Deng J., Cai K.Q., Zhou Y., Wang Q.F., Zhou Y.H., Gao B.F., De xiu L.I., Fu yu X.U. and Zhu Y.R. (2005) Mineralogical characteristics of beryl in Pingwu County, Sichuan Province, south-west China. Earth Science Frontiers, 12, 324-331.

Liu Y., Deng J., Li G. and Shi G. (2007) Structure refinement of Cs-rich Na-Li beryl and analysis of its typomorphic characteristics of configurations. Acta Geologica Sinica, 81, 61-67.

Liu Y., Deng J., Shi G. and Sun D. (2012) Geochemical and morphological characteristics of coarse-grained tabular beryl from the Xuebaoding W$\mathrm{Sn}-\mathrm{Be}$ deposit, Sichuan Province, western China. International Geology Review, 54, 1673-1684.

Łodziński M., Sitarz M., Stec K., Kozanecki M., Fojud Z. and Jurga S. (2005) ICP, IR, Raman, NMR investigations of beryls from pegmatites of the Sudety Mts. Journal of Molecular Structure, 744-747, 1005-1015.

Lum J.E., Viljoen F., Cairncross B. and Frei D. (2016) Mineralogical and geochemical characteristics of beryl (aquamarine) from the Erongo Volcanic Complex, Namibia. Journal of African Earth Sciences, 124, 104-125.

Mashkovtsev R.I., Thomas V.G., Fursenko D.A., Zhukova E.S., Uskov V. V. and Gorshunov B.P. (2016) FTIR spectroscopy of D2O and HDO molecules in the $c$-axis channels of synthetic beryl. American Mineralogist, 101, 175-180.

Mihalynuk M.G. and Lett R. (2003) Composition of Logtung beryl (aquamarine) by ICPES/MS: a comparison of beryl worldwide. Pp. 141-146 in: Geological Fieldwork. Crown Publications Inc., British Columbia, Canada.

Neiva A.M.R. and Neiva J.M.C. (2005) Beryl from the granitic pegmatite at Namivo, Alto Ligonha, Mozambique. Neues Jahrbuch für Mineralogie Abhandlungen, 181, 173-182.

Ottens B. (2005) Xuebaoding: Pingwu County, Sichuan Province, China. Mineralogical Record, 36, 45-57.

Pankrath R. and Langer K. (2002) Molecular water in beryl, ${ }^{\mathrm{VI}} \mathrm{Al}_{2}\left[\mathrm{Be}_{3} \mathrm{Si}_{6} \mathrm{O}_{18}\right]$ $\cdot \mathrm{nH}_{2} \mathrm{O}$, as a function of pressure and temperature: An experimental study. American Mineralogist, 87, 238-244.

Pauly C. (2019) Mineralogy and Petrogenesis of the California Blue Mine Aquamarine- and Topaz-Bearing Pegmatite Deposit, San Bernardino County, California. Colorado School of Mines, USA.

Qi L., Ye S., Xiang C., Pei J. and Luo Y. (2001a) Color center and coloring mechanism of irradiated beryl. Geological Science and Technology Information, 20, 68-72.

Qi L., Pei J., Zhou K., Shi G. and Luo Y. (2001b) Crystal defect and growth mechanism of alkali-rich beryl crystal from Pingwu, Sichuan, China. Geological Science and Technology Information, 20, 64-70.

Qi L., Xiang C., Liu G., Pei J. and Luo Y. (2001c) ESR behaviour of paramagnetic mixture in irradiated beryl. Geological Science and Technology Information, 20, 59-64.

Qi L., Ye S., Xiang C., Pei J. and Shi G. (2001d) Vibration spectrum and irradiation splitting of mixture in beryl channels. Geological Science and Technology Information, 20, 59-64.

Robinson K., Gibbs G.V. and Ribbe P.H. (1971) Quadratic elongation: a quantitative measure of distortion in coordination polyhedra. Science, 172, 567-570.

Roger F., Malavieille J., Leloup P.H., Calassou S. and Xu Z. (2004) Timing of granite emplacement and cooling in the Songpan-Garzê fold belt (eastern Tibetan Plateau) with tectonic implications. Journal of Asian Earth Sciences, 22, 465-481.
Roger F., Jolivet M. and Malavieille J. (2010) The tectonic evolution of the Songpan-Garzê (North Tibet) and adjacent areas from Proterozoic to Present: A synthesis. Journal of Asian Earth Sciences, 39, 254-269.

Sardi F.G. and Heimann A. (2014) Pegmatitic beryl as indicator of melt evolution: example from the Belasco district, Pampeana pegmatite province, Argentina, and review of worldwide occurrences. The Canadian Mineralogist, 52, 809-836.

Scandale E. and Lucchesi S. (2000) Growth and sector zoning in a beryl crystal. European Journal of Mineralogy, 12, 357-366.

Scandale E., Lucchesi S. and Graziani G. (1990) Growth defects and growth marks in pegmatite beryls. European Journal of Mineralogy, 2, 305-312.

Sheldrick G.M. (2008) A short history of SHELX. Acta Crystallographica, A64, 112-122.

Sherriff B.L., Grundy H.D., Hartman J.S., Hawthorne F.C. and Černý P. (1991) The incorporation of alkalis in beryl; a multinuclear MAS NMR and crystalstructure study. The Canadian Mineralogist, 29, 271-285.

Sunagawa I. (1984) Growth of crystals in nature. Pp. 61-103 in: Materials Science of the Earth's Interior. Terra Scientific Publishing, Tokyo.

Tempesta G., Scandale E. and Agrosì G. (2011) Striations and hollow channels in rounded beryl crystals. Periodico di Mineralogia, 79, 75-87.

Tempesta G., Bosi F. and Agrosì G. (2020) Crystal chemical characterisation of red beryl by 'Standardless' laser-induced breakdown spectroscopy and single-crystal refinement by X-Ray diffraction: An example of validation of an innovative method for the chemical analysis of minerals. Geostandards and Geoanalytical Research, 44, 685-693.

Uher P., Chudík P., Bačík P., Vaculovič T. and Galliová M. (2010) Beryl composition and evolution trends: an example from granitic pegmatites of the beryl-columbite subtype, Western Carpathians, Slovakia. Journal of Geosciences, 55, 69-80.

Wang R., Cheng Che X., Dong Zhang W., Lan Zhang A. and Cheng Zhang H. (2009) Geochemical evolution and late re-equilibration of NaCs-rich beryl from the Koktokay \#3 pegmatite (Altai, NW China). European Journal of Mineralogy, 21, 795-809.

Wood D.L. and Nassau K. (1967) Infrared spectra of foreign molecules in beryl. The Journal of Chemical Physics, 47, 2220-2228.

Wood D.L. and Nassau K. (1968) The characterization of beryl and emerald by visible and infrared absorption spectroscopy. American Mineralogist, 53, 777-800.

Xiao L., Zhang H.F., Clemens J.D., Wang Q.W., Kan Z.Z., Wang K.M., Ni P.Z. and Liu X.M. (2007) Late Triassic granitoids of the eastern margin of the Tibetan Plateau: Geochronology, petrogenesis and implications for tectonic evolution. Lithos, 96, 436-452.

Xu Z., Hou L., Wang Z., Fu X. and Huang M. (1992) Orogenic Processes of the Songpan Ganze Orogenic Belt of China. Geological Publishing House, Beijing.

Yakubovich O.V., Pekov I.V., Steele I.M., Massa W. and Chukanov N.V. (2009) Alkali metals in beryl and their role in the formation of derivative structural motifs: Comparative crystal chemistry of vorobyevite and pezzottaite. Crystallography Reports, 54, 399-412.

Ye S., Qi L., Luo Y., Zhou K. and Pei J. (2001) Relationship between the rare-metal contained granitic intrusions and beryl mineralization in Pingwu, Sichuan, China. Geological Science and Technology Information, 20, 65-70.

Zhang D., Peng J., Coulson I.M., Hou L. and Li S. (2014) Cassiterite U-Pb and muscovite ${ }^{40} \mathrm{Ar}-{ }^{39} \mathrm{Ar}$ age constraints on the timing of mineralization in the Xuebaoding Sn-W-Be deposit, western China. Ore Geology Reviews, 62, 315-322.

Zhang L., Ruan Q. and Rao C. (2012) The crystal growth and characteristics of etched figures on $c\{0001\}$ face of tabular beryl crystal from Pingwu, China. Acta Mineralogica Sinica, 32, 1-8.

Zhou K., Qi L., Xiang C., Feng Q., Wu J. and Hao Q. (2002) Geologic characteristic of forming beryl gem from Pingwu Sichuan. Journal of Mineralogy and Petrology, 22, 1-7.

Zhu X., Raschke M.B. and Liu Y. (2020) Tourmaline as a recorder of oreforming processes in the Xuebaoding W-Sn-Be deposit, Sichuan province, China: Evidence from the chemical composition of tourmaline. Minerals, 10, 438 . 